\title{
Human papilloma virus: Apprehending the link with carcinogenesis and unveiling new research avenues (Review)
}

\author{
DANIEL BODA $^{1,2^{*}}$, ANCA OANA DOCEA $^{3 *}$, DANIELA CALINA $^{4 *}$, \\ MIHAELA ADRIANA ILIE ${ }^{1,5}$, CONSTANTIN CARUNTU ${ }^{1,2,6}$, SABINA ZURAC $^{7,8}$, \\ MONICA NEAGU $^{9}$, CAROLINA CONSTANTIN ${ }^{9}$, DACIANA ELENA BRANISTEANU ${ }^{10}$, \\ VLAD VOICULESCU $^{11}$, CHARALAMPOS MAMOULAKIS ${ }^{12}$, GEORGE TZANAKAKIS ${ }^{13}$, \\ DEMETRIOS A. SPANDIDOS ${ }^{14}$, NIKOLAOS DRAKOULIS ${ }^{15}$ and ARISTIDES M. TSATSAKIS ${ }^{16}$
}

\begin{abstract}
${ }^{1}$ Dermatology Research Laboratory, 'Carol Davila' University of Medicine and Pharmacy, 030167 Bucharest;
${ }^{2}$ Department of Dermatology, 'Prof. N. Paulescu' National Institute of Diabetes, Nutrition and Metabolic Diseases, 011233 Bucharest; Departments of ${ }^{3}$ Toxicology and ${ }^{4}$ Clinical Pharmacy, University of Medicine and Pharmacy of Craiova, 200349 Craiova; Departments of ${ }^{5}$ Biochemistry, ${ }^{6}$ Physiology and ${ }^{7}$ Pathology, 'Carol Davila' University of Medicine and Pharmacy, 030167 Bucharest; ${ }^{8}$ Colentina University Hospital, Sector 2 19-21, Bucharest; ${ }^{9}$ 'Victor Babes’ National Institute of Pathology, 050096 Bucharest; ${ }^{10}$ Department of Dermatology, 'Gr. T. Popa' University of Medicine and Pharmacy, 700115 Iasi; ${ }^{11}$ Department of Dermatology and Allergology, Elias Emergency University Hospital, 011461 Bucharest, Romania; ${ }^{12}$ Department of Urology, University General Hospital of Heraklion, University of Crete Medical School;

${ }^{13}$ Laboratory of Anatomy-Histology-Embryology, and ${ }^{14}$ Laboratory of Clinical Virology, Medical School, University of Crete, 71003 Heraklion, Crete; ${ }^{15}$ Research Group of Clinical Pharmacology and Pharmacogenomics, Faculty of Pharmacy, School of Health Sciences, National and Kapodistrian University of Athens, 15771 Athens; ${ }^{16}$ Laboratory of Toxicology, Medical School, University of Crete, 71003 Heraklion, Crete, Greece
\end{abstract}

Received September 9, 2017; Accepted December 28, 2017

DOI: $10.3892 / \mathrm{ijo} .2018 .4256$

\begin{abstract}
Human papilloma viruses (HPV) are a small group of non-enveloped viruses belonging to the Papillomaviridae family with strong similarities to polyoma viruses. The viral particles consist of a genome in the form of a circular double-stranded DNA, encompassing eight open reading frames, as well as a non-enveloped icosahedral capsid. HPV infection is considered the most common sexually transmitted disease in both sexes and
\end{abstract}

Correspondence to: Professor Aristides M. Tsatsakis, Laboratory of Toxicology, Medical School, University of Crete, Voutes Campus, 71003 Heraklion, Crete, Greece

E-mail: tsatsaka@uoc.gr

Professor Nikolaos Drakoulis, Research Group of Clinical Pharmacology and Pharmacogenomics, Faculty of Pharmacy, School of Health Sciences, National and Kapodistrian University of Athens, Panepistimiopolis Zografou, 15771 Athens, Greece

E-mail: drakoulis@pharm.uoa.gr

*Contributed equally

Key words: genital neoplasms, female, fenital neoplasms, male, head and neck neoplasms, human papilloma virus, neoplasms, Papillomaviridae, penile neoplasms, uterine cervical neoplasms, vaginal neoplasms, vulvar neoplasms is strongly implicated in the pathogenesis of different types of cancer. 'High-risk' mucosal HPV types, predominantly types 16 , 18,31,33 and 35, are associated with most cervical, penile, vulvar, vaginal, anal, oropharyngeal cancers and pre-cancers. Screening for HPV is necessary for the prognosis and for determining treatment strategies for cancer. Novel HPV markers, including proteomic and genomic markers, as well as anti-papillomavirus vaccines are currently available. The aim of this comprehensive review was to thoroughly present the updated information on virus development, cancer occurrence, treatment and prevention strategies, in an attempt to shed further light into the field, including novel research avenues.

\section{Contents}

1. HPV in the general context

2. Development of HPV infections

3. Tendencies in cancer occurrence in specific epithelial areas

4. Conditions favoring HPV development

5. HPV occurrence in comparison to other sexually transmitted diseases

6. HPV persistence and cancer incidence

7. HPV prevention

8. Proteomics technologies for the identification of markers

9. HPV markers

10. HPV treatment and cancer

11. Conclusions 


\section{HPV in the general context}

Human papilloma viruses (HPVs) are a small group of non-enveloped viruses belonging to the Papillomaviridae family with strong similarities to polyoma viruses (1). The viral particles consist of a genome in the form of a circular double-stranded DNA, encompassing eight open reading frames, as well as a non-enveloped icosahedral capsid. Their size is approximately $52-55 \mathrm{~nm}$ and they are composed of 72 pentameric capsomers (2). To date, $>170$ types of HPV have been identified (3), the majority of which affect the genital tract epithelia (approximately half of them), the mucosa of the upper respiratory tract and the skin developing epidermodysplasia verruciformis $(3,4)$. 'High-risk' mucosal HPV types, predominantly types $16,18,31,33$ and 35 , have been associated with most cervical, penile, vulvar, vaginal, anal and oropharyngeal cancers and pre-cancers (5). HPV types 16 and 18 are the most common high-risk types and are considered to be responsible for $>70 \%$ of all cervical cancer cases (5).

HPV are characterized by the presence of three functional code regions in their genome: The $\mathrm{E}$ region that codes the early viral function, the $\mathrm{L}$ region which is responsible for the late viral function and the long control region (LCR) that is situated between the previous regions. The density of an intact virion is approximately $1.34 \mathrm{~g} / \mathrm{ml}$ in cesium chloride and a sedimentation coefficient (S20, W) of 300 (6).

The link between HPV and cancer has been extensively investigated over the past decade and, for this discovery, Professor Harald zur Hausen, the 'Father of HPV Virology', received the Nobel Prize (7). 'Low-risk' HPV types cause benign anogenital warts and recurrent respiratory papillomatosis and are only rarely found in squamous intraepithelial lesions (8).

Despite the fact that HPVs are known to be responsible for the development of cervical cancers, HPV infections are often asymptomatic, unrecognized and underestimated. The Center for Disease Control and Prevention (CDC) highlights the fact that the majority of sexually active individuals become infected with HPV at least once in their lifetime (9), often without being aware and not presenting any symptoms. HPV infection is considered the most common sexually transmitted disease among both males and females. Indeed, HPV-associated cervical cancer is one of the most prevalent types of cancer over the past years and the third main cause of cancer-related mortality among adults (9). Furthermore, HPV types 16 and 18 high-risk genital types are implicated in the majority of ano-genital tract malignancies, while HPV types 6 and 11 are considered to be low-risk HPV types, which induce laryngeal papillomatosis and genital warts. Other identified genital HPV types are: $31,33,35,39,45,51,52,56,58,66$ and 69 (10).

It has recently been demonstrated that in the USA, women are twice more likely to develop a HPV infection than men, and that the prevalence of HPV is much higher in women than in men, the peak time for acquiring the infection being shortly after becoming sexually active (11). In the majority of HPV-infected individuals, the virus will clear out naturally, without the individual being aware they were infected or exposed to the virus. An immune-deficient woman will develop cervical cancer within 5 to 10 years, while for a woman with a normal immune system; this time frame may be extended up to 15 to 20 years or even longer (11).
Oropharyngeal cancer can be induced by members of the HPV family, among which HPV type 11 is the most prevalent, with a percentage of $50-84 \%$ being the cause of causing laryngeal papillomatosis. Even so, in the adult population, HPV 16 is the type most commonly associated with cancer incidence, being correlated to $86 \%$ of all HPV-related cancers. Thus, HPV type 16 has been identified both in upper respiratory tract papillomatosis, but also in the normal mucosa adjacent to lesions (12). It has been demonstrated that tonsilar cancer in particular, has a strong association with HPV (approximately $60 \%$ this type of cancer is ascribed to HPV) (12).

\section{Development of HPV infections}

Oncogenic high-risk associated HPV strains have the strongest contribution to the occurrence of pre-cancerous and cancerous lesions (11). Age trends in cervical HPV acquisition and persistence have revealed that with age, the incidence of new infections decreases, while persistence increases, emphasizing the utility of HPV screening in older women (13). This may result from age-related immune senescence affecting HPV clearance, the reduced size of squamocolumnar junctions and the replacement of the cervical mucosa by atrophic stratified squamous epithelium (13). Of note, HPV DNA is present in oral and genital samples of asymptomatic neonates soon after birth (14) and it has been suggested that HPV infection can be acquired very early in infancy (15) in utero via the placenta or cord blood, perinatally or through maternal breast milk. High carriage rates of HPV DNA have been detected in oral samples from newborn babies (16) that decrease gradually during the first 3 years of life (16). Moreover, 'high-risk' mucosal types have been detected in genital samples obtained from asymptomatic infants, with a decreasing genital HPV DNA carriage rate during the first year of life (16).

In a recent Romanian study, only $15 \%$ of individuals tested positive for HPV had low-risk strains, while the remainder had either high-risk or mixed high- and low-risk strain infections. The distribution of high-risk HPV strains was found to prevail in women younger than 35 years, indicating that additional attention may be necessary for this age group regarding the risk of the development of HPV-related neoplasms (17).

HPVs, including high-risk types 16 and 18, have also been detected in tonsillar or adenoid samples from children with tonsillar or adenoid hyperplasia, chronic tonsillitis and normal mucosa (18), as well as in genital samples from pre-pubertal girls with no known vulvar disease (19). A so-called 'Trojan horse oncogenic strategy' for HPV in childhood has been proposed, stating that children may represent a reservoir of 'silent' high-risk HPV types that may be the key to HPV persistence and related carcinogenesis later on in adulthood (6).

However, apart from persistent HPV infection, other viral, host and environmental co-factors (20), as well as psychological stressors (21-23) have been proposed to be involved in HPV-related carcinogenesis. Oxidative stress is generated in aerobic cells during infections, inflammation, physical, mechanical and chemical stresses and it promotes viral infection, viral persistence and the integration of the viral DNA into the host genome (20). HPV-infected epithelial surfaces are a constant target for oxidative stress-induced genotoxic, anti-apoptotic and pro-angiogenetic effects and also for oxidative stress/HPV 
cooperation in initiating and promoting carcinogenesis (20). Oxidative stress promotes the activator protein-1-mediated expression of the $E 6$ and $E 7$ viral oncogenes that further target and promote the degradation of p53 and some members of the retinoblastoma protein family, leading to genomic alterations, the inhibition of apoptosis and neoplasia (20).

\section{Tendencies in cancer occurrence in specific epithelial areas}

High-risk HPV are causally associated with $99 \%$ of cervical, $25 \%$ of head and neck, $70 \%$ of vaginal, $88 \%$ of anal, $43 \%$ of vulvar and $50 \%$ of penile carcinomas, in descending order by prevalence $(1,24-27)$. While the incidence of cervical cancer has declined steadily due to intensive screening programs, the incidence of $\mathrm{HPV}$-positive $\left(\mathrm{HPV}^{+}\right)$head and neck carcinomas has significantly increased over the past decades (25), becoming the second most common localization for HPV-associated tumors $(1,25)$. By the year 2020, the annual number of $\mathrm{HPV}^{+}$ head and neck carcinomas has been estimated to be the highest among HPV-associated cancers in the USA (12). Importantly, $\mathrm{HPV}^{+}$and $\mathrm{HPV}$-negative (HPV ${ }^{-}$) head and neck carcinomas have been proven to be different clinical entities in terms of risk factors, anatomical sites of involvement, molecular alterations, pathology appearance and prognosis (28). $\mathrm{HPV}^{+}$head and neck carcinomas primary involve the oropharynx (tonsils, base of the tongue and other parts of the oropharynx) (24) and are caused by HPV type 16 in $>90 \%$ of cases (25). It has been demonstrated that the $E 6$ and $E 7$ genes are the main viral oncogenes by which HPV 16 and other high-risk HPV inactivate $\mathrm{p} 53$ and retinoblastoma protein, respectively, leading to the inhibition of apoptosis, cell cycle progression $(1,24)$, the accumulation of genetic alterations, viral integration and ultimately to uncontrolled cell proliferation $(20,29)$. Experimental data have indicated that the expression of $E 6 / E 7$ is mandatory for the initiation and maintenance of the malignant phenotype in oropharyngeal cancers (28). By contrast, HPV-related head and neck carcinomas are associated with exposure to tobacco and alcohol consumption, with the incidence decreasing in developed countries due to aggressive smoking cessation campaigns (30).

Furthermore, HPV positivity is associated with a significantly superior loco regional control (30) and a better prognosis of recurrent/metastatic head and neck carcinoma (31). In fact, the tumor HPV status is of paramount importance in predicting the survival for patients with local regionally advanced oropharyngeal cancer and its determination is included in the routine evaluation of head and neck cancers for prognostic assessment (28). The biological explanation for these different outcomes is currently unknown and, as in other pathologies (32), the novel '-omics' technologies are promising in the pinpointing of reliable biomarkers useful for patient stratification, the evaluation of therapeutic regimens and identification of potentially targetable pathogenic pathways (30). Of note, HPV-related head and neck carcinomas share molecular characteristics with lung squamous carcinoma, whereas $\mathrm{HPV}^{+}$-related head and neck carcinomas have similar characteristics with cervical neoplasia (33). This latter observation can be in part explained by the fact that oral HPV infection and type concordance in women with cervical HPV infection are frequent, and increase significantly in human immunodeficiency virus (HIV) infection, demonstrating a degree of correlation between the two infection sites (34).

HPV infection is an important risk factor for penile SCC, the most frequently reported pathology of penile cancer $(>95 \%)$. It is a rare malignancy accounting for $0.24 \%$ of all neoplasms among males in the United States with a significantly higher incidence (up to 20-30-fold greater) in areas of Africa and South America that usually arises from the epithelium of the inner prepuce or the glans, and it exists in several histological subtypes sharing a similar pathology with SCC of other origins (35-38). Viral DNA has been detected in 70-100\% of penile intraepithelial neoplasia and in 30-40\% of invasive cancer tissue samples (35). HPV infection (particularly by the high-risk HPV 16, 18, 31, 33, 45, 56 and 65) is nowadays recognized as a major co-factor in penile SCC through interaction with oncogenes and tumor suppressor genes ( $p 53$, retinoblastoma protein, p16) $(37,39)$. Nevertheless, it is now clear that apart from the HPV-induced pathway (through which up to $50-80 \%$ of penile SCC cases arise), a non-HPV-induced pathway represents a divergent molecular pathway accounting for penile carcinogenesis related to several risk factors, such as chronic inflammation and specific mediators $(37,40)$.

\section{Conditions favoring HPV development}

HPV enters epithelial cells of cutaneous or mucosal surfaces through abrasion (6) and further requires wounding or micro-wounding in order to allow the access of the virus to the basal lamina (41). In most cases, HPV infection resolves spontaneously and is transient and asymptomatic (42). The development of HPV infections and lesion formation may involve the appearance of the wound healing response that promotes active cell division and the proliferation of infected cells $(29,43,44)$

Persistent infection with high-risk HPV types and altered viral gene expression are the cornerstone of HPV-induced carcinogenesis (29). Life-cycles of low-risk and high-risk HPV types differ in their ability to drive cell cycle entry and enhance cell proliferation in the basal cell layers (29). The E6 and $E 7$ viral oncogenes are considered to have a significant contribution to these differences, as E6 inactivates $p 53$ and E7 promotes the degradation of several retinoblastoma protein family members, further leading to cell cycle deregulation and the inhibition of p53-mediated apoptosis $(1,25,29)$. Moreover, while HPV infection requires the appearance of wound healing and inflammation, in some cases, pro-inflammatory cytokines/chemokines can trigger malignant transformation. Tumor-induced inflammation in turn can promote the proliferation and survival of malignant cells and may alter the response to cancer-targeted therapeutic agents (45).

However, only a small fraction of infections with high-risk HPV types will eventually evolve into ano-genital or head and neck carcinomas and various co-factors have been proposed to be involved in the progression of HPV infection in the epithelial neoplasia. The most consistently identified factors in HPV-related carcinogenesis include high parity, the long-term use of oral contraceptives, smoking, concomitant infection with other sexually transmitted agents (46), the immune status, nutrition, endogenous and exogenous hormones, as well 
Table I. Incidence and prevalence of the most frequent sexually transmitted diseases.

\begin{tabular}{lccrr}
\hline STD & World incidence & World prevalence & US incidence & US prevalence \\
\hline 1. HPV & N/A & $291,000,000$ & $14,100,000$ & $79,100,000$ \\
2. Chlamydia & $130,900,000$ & N/A & $2,860,000$ & $24,100,000$ \\
3. Trichomoniasis & $142,600,000$ & N/A & $1,090,000$ & $3,710,000$ \\
4. Gonorrhea & $78,300,000$ & N/A & 820,000 & $1,570,000$ \\
5. Syphilis & $5,600,000$ & N/A & 55,400 & 422,000 \\
6. HSV & N/A & $417,000,000$ & 776,000 & 908,000 \\
7. HIV & $1,800,000$ & $36,700,000$ & 41,400 & 270,000 \\
8. Hepatitis B & N/A & $248,000,000$ & 19,000 & 117,000
\end{tabular}

STD, sexually transmitted disease; HPV, human papilloma virus; HSV, herpes simplex virus; HIV, human immunodeficiency virus; N/A, not applicable.

as viral characteristics, such as HPV type, viral load, HPV variant and viral integration $(42,47)$.

\section{HPV occurrence in comparison to other sexually transmitted diseases}

HPV is the most prevalent sexually transmitted infection worldwide (48-50), associated with a profound social and economic burden (51). In fact, the majority of sexually active individuals contract at least one type of HPV at some point in their lives; however, in the majority of cases, HPV infection is transient or asymptomatic and is resolved spontaneously (42). Therefore, it is considered appropriate that treatment is vindicable only for clinically visible or microscopically pre-cancerous lesions caused by HPV and is not recommended for the virus itself (42). However, new evidence suggests that the early detection of known high-risk HPV infection and treatment should be considered even if clinically or microscopically pre-cancerous lesions are not visible. This early detection is not currently available on a routine basis; thus, the development of newer molecular genetic diagnosis methods is mandatory.

Many types of HPV are sexually transmitted through the ano-genital contact, mainly during vaginal and anal sex, and also during genital-to-genital contact without penetration and oral sex (42). Exceptionally, HPV may be transmitted by non-sexual routes, including casual physical contact via autoinoculation or fomites, as well as vertically from HPV-infected pregnant women to their newborns during delivery $(1,6,42)$ or in utero (14). In a 2015 report on global sexually transmitted infection surveillance, WHO estimated that worldwide, $>290$ million sexually active women will at some point become infected with HPV and an estimated 417 million cases are prevalent for herpes simplex viral infection $(52,53)$. Male prevalence is not yet known, although it may be even higher due to the high clinically asymptomatic rates. For a comparison, the global estimate in incidence for the most common sexually transmitted infections that are considered curable (chlamydia, gonorrhoea, trichomoniasis, and syphilis) was approximately $357 \times 10^{6}$ new infections in 2012 (Table I) (54).

In 2013, CDC published the latest available data for the US, demonstrating that roughly $>6 \%$ of Americans annually contract a new sexually transmitted infection and approximately
1 in 3 Americans have a sexually transmitted infection (numbers corresponding to an incidence of $19.7 \times 10^{6}$ and a prevalence of $110 \times 10^{6}$ sexually transmitted infections at a population of $304,09 \times 10^{6}$ for the year 2008), with an estimated economic burden of over $16 \times 10^{9}$ US \$ with $3 \times 10^{9}$ US \$ in direct medical costs (in 2010). Of great concern is the fact that $>20 \%$ of these infections $\left(22.1 \times 10^{6}\right)$ with an acquisition rate of almost $9.8 \times 10^{6}$ a year were among men and women aged 15 to 24 years, which in many cases were not clinically evident, accounting for most of both prevalent and incident infections $(48,51)$.

Although there is no reporting system for HPV in the USA, more conclusive data is available through CDC statistics. As stated in a recent brief, among adults aged between 18-69 years in 2013-2014, approximately $45 \%$ of men and $40 \%$ of women had a genital HPV infection. Approximately $25 \%$ of men and $20 \%$ of women had a high-risk genital HPV infection. The prevalence of any type of oral HPV infection among adults aged between 18-69 years in 2011-2014 was approximately $7 \%$, and the prevalence of high-risk oral HPV infection was $4 \%$ (55). The vast majority of HPV infections (approximately 90\%) are spontaneously resolved within 1 or 2 years, being cleared by the immune system $(56,57)$.

An increasing amount of data suggests that HPV infection, even asymptomatic, can significantly increase the morbidity associated with other sexually transmitted diseases. In a recent study, it was shown that reduced sperm motility/abnormal morphology significantly decreased fertility in a male heterosexual population with prostatitis-related symptoms secondary to Chlamydia trachomatis and HPV co-infection (58). In another study, Chlamydia trachomatis infection in both $\mathrm{HPV}^{+}$ and $\mathrm{HPV}^{-}$females was investigated (59). It was concluded that Chlamydia trachomatis infection was much more prevalent in $\mathrm{HPV}^{+}$subjects and when the two sexually transmitted infections co-existed, there was an increased risk for detecting single high-risk HPV genotypes and various multiple HPV infections even in asymptomatic patients. Chlamydia trachomatis infection was investigated as a potential HPV co-factor in invasive cervical cancer as early as 2002. Smith et al investigated a Brazilian and Philippinese invasive cervical cancer population and found that Chlamydia trachomatis infection increased the risk of developing SCC among $\mathrm{HPV}^{+}$patients (60). Although a direct interaction between Chlamydia trachomatis and HPV 
was not yet demonstrated, the authors of that study postulated that Chlamydia trachomatis can act as a carcinogenic co-factor by means of chronic inflammation, in which reactive oxygen species may damage DNA, thus providing a possible link towards malignant transformation (60).

Another study identified a possible association between HPV and hepatitis $C$ virus. In liver transplant candidates, $\mathrm{HPV}^{+}$testing was prevalent in non-sexually active women, suggesting a possible reactivation of dormant HPV due to a dysregulation in T-cell activity by the hepatitis C virus (61). Genital herpes virus (HSV-2) infection was long thought to be a co-factor in cervical cancer development (62). On its own, HSV-2 infection represents a social and economic burden, with approximately $1.1 \times 10^{6}$ individuals $(15.9 \%)$ reporting asymptomatic genital herpes and $47 \times 10^{6}$ new cases in 2013 (63). It has been suggested that in conjunction with HPV, HSV can accelerate the process of tumorigenesis, in part due to the repeated inflammation caused by its periodic outbursts. Yet, this theory remains to be validated, since HSV was not present in all cervical cancer tissue samples as opposed to HPV. In another study in a population of genital HPV-infected men, it was found that that Chlamydia trachomatis and HSV-2 infections were more prevalent (64). However, it remains uncertain as to whether these infections can influence the acquisition and/or persistence of HPV through a biological interaction, such as a decrease in cell-mediated immunity (64).

There is evidence that HIV infection $\left(>35 \times 10^{6}\right.$ cases worldwide with approximately $1.8 \times 10^{6}$ new ones in 2016) can increase the number of infected HPV particles carried on a single individual (http://www.who.int/mediacentre/ factsheets/fs360/en). This may be the result of the negative impact of HIV on the immune system functionality. Among couples, HIV infection can impact HPV carriage. It has been reported that in couples where women are HIV-positive, their HIV-negative male partners have a significantly higher rate of HPV penile carriage compared to those of HIV-negative women (58 vs. $32 \%$ ) (65). If both partners are HIV positive, the carriage rate increases to $72 \%$. Moreover, HIV co-infection increases the risk of type-specific HPV sharing within the couple (65). Furthermore, two large meta-analyses, performed in women from the general population and in HIV-positive women, revealed that HPV prevalence was higher within the same region in HIV-positive compared to HIV-negative individuals $(66,67)$.

\section{HPV persistence and cancer incidence}

CDC outlines that in approximately $90 \%$ of cases, HPV infection is likely to disappear within approximately two years, causing no harmful effects. However, if there is a persistent infection, due to high-risk strain HPV strains, coupled with host-particularities, particular behavior such as smoking and/or alcohol abuse, environmental co-factors, other associated viral infection such as HIV, persistence can lead to neoplastic transformation $(9,25,34,68,69)$. The link between well-studied genital cancer and oral cancer triggered by persistent HPV infections is still a subject of intense investigation (70). High-grade cervical intraepithelial neoplasia and the association with HPV have been studied in various cohorts and geographical regions. In over 8,600 Danish women tested at 2 years, it was reported that subjects that tested positive for HPV type 16 at the second examination had an estimated probability of developing CIN grade 3 within 12 years of $26.7 \%$, while those infected with HPV type 18 of $19.1 \%$ (71). This study revealed that the persistence of HPV type 16 was particularly associated with a high risk to develop high-grade cervical lesions (71). In >2,000 women from Africa, HPV prevalence was reported as $24.5 \%$ for any HPV type and as $16.1 \%$ for the oncogenic ones. Over 21 months of follow-up, type-specific persistence was $29.8 \%$ among all HPV infections giving good grounds for vaccine development (72).

In a Finish female cohort, the natural HPV type 16 clearance of patients with positive cervical and oral samples was investigated. Natural clearance correlated with HPV antibody titers (73). In this context, it was reported that a duration of HPV persistence of $>12$ months leads to an increased risk for disease progression in cervical and oral neoplasias $(73,74)$. In high-grade squamous intraepithelial lesions, an extended high-risk HPV persistence of $>6$ months was the most potent predictor of progression (74). Later on, when HPV vaccines were investigated, the results obtained from a study comprising over 15,000 female subjects confirmed that a persistence of HPV infection of $>6$ months was the surrogate endpoint of progressive disease (75). In oral mucosa infection, HPV type 16 was the main cause of infection (65\%), other low-risk HPV genotypes cleared from the oral mucosa rapidly in comparison to the high-risk HPV genotypes 12 (75).

When investigating the association between HPV infection with oropharyngeal and anogenital sites in men engaging in sexual activities with other men, no congruity between HPV genotypes discovered at oral sites as compared with the anogenital sites was found; thus, it is possible that oral HPV infection may be considered independently (76). In esophageal SCC diagnosed in a Greek population, it was reported that there are important positive association factors, such as HPV positivity, the mutational activation of K-ras and tobacco/alcohol abuse, that are main risk factors for the development of this type of cancer $(30,77)$.

HPV infection can trigger cervical cancer, accounting for approximately $25 \%$ of head and neck cancer cases (78). In female subjects, there is an increased prevalence of oral HPV infections with concomitant cervical HPV infection with a moderate type-specific HPV concordance between genital and oral HPV types. The long-term persistence of cervical high-risk HPV (over 24 months of positivity), can induce an increased incidence of oral HPV infection later in time. Lower titers of HPV type 16 antibodies may suggest the incapacity to clear chronic cervical HPV infections (79).

Despite prior findings demonstrating the lack of a correlation between the oral finding of HPV DNA and HPV serology, there are data showing the most marked titers of HPV type-specific antibodies in female subjects clearing cervical HPV type 16 infection and the lowest HPV type 16 antibody levels in females with acquired cervical HPV type 16 infections (72). There are also studies suggesting the possibility of a subcategory of women with HPV persistence at a very young age $(72,80,81)$. A study conducted by Koskimaa et al in children whose mothers had cervical intra-epithelial neoplasm lesions, demonstrated that these children had HPV type 16-specific cell-mediated immunity. HPV infections persistent earlier in 
life can affect the outcome of subsequent genital or oral HPV infections (82).

In terms of the clinical manifestation of HPV infection, these may vary from asymptomatic forms, beginning from benign warts and ending in carcinomas of malignant potential (17). In an attempt to elucidate the presence of benign warts as a site of persistence for future neoplastic transformation, Kofoed et al conducted a study including 201 men and women with genital wart-like lesions (83). Their study found HPV in $46.2 \%$ of subjects, out of which oral HPV was identified in $10.4 \%$ of subjects. In $21.7 \%$ of investigated subjects, concordance was found between oral and anal HPV types. Patients with genital warts frequently display extra-genital HPV with differences between men and women subjects (83).

HPV infection has specific sites for localization. In order to complete the HPV infection generation cycle, the virus requires a stratified epithelium. That is why HPV-associated cancers occur in areas with intermediate epithelia towards cubic mucosal epithelia, such as the lip, cervix, oral cavity or the rectum (29). The usual progression begins with initial virus infestation of the basal cell nucleus, overcoming the host defense mechanisms. Once established in the basal cell nucleus, the virus genome multiplies with the host DNA, producing a reduced number of copies which later, on cell division, are allocated to daughter cells. In this phase, there is a low viral gene expression, and thus infected cells are difficult to detect (84). In light of the overall body of evidence, the vast majority of HPV infections (approximately 90\%) are cleared naturally by the body's immune system within a two-year period; however, when persistence is established for $>6$ months, infection induces a high risk of the malignant transformation of infected cells.

\section{HPV prevention}

Sexual abstinence is the most reliable method of protection against HPV, as with other sexually transmitted infections $(8,9)$. Limiting the number of lifetime sexual partners, cultivating a monogamous relationship and having safe sexual habits can reduce the exposure to HPV (85). The consistent and correct use of condoms, although not offering complete protection, can decrease the risk of transmitting HPV and developing HPV-associated conditions $(8,9)$.

Available vaccines (bivalent, quadrivalent and 9-valent vaccines) are effective against high-risk HPV types 16 and 18 , and are the optimal prevention strategy for cervical cancer to date (11). The quadrivalent vaccine also protects against HPV types 6 and 11, which are responsible for $90 \%$ of ano-genital warts; whereas the 9-valent vaccine also covers HPV types 31 , $33,45,52$ and 58, that account for $15 \%$ of cervical cancer cases $(8,9)$. All vaccine types are safe and should be administered as a 3-dose series of intra-muscular injections over a 6-month period for the female population aged 11-12 years, but vaccination can begin 9 years of age (86). Boys are advised to receive the quadrivalent (11) or the 9-valent $\operatorname{HPV}(8,9)$ vaccine at the same age interval as girls. HPV vaccines can be administered regardless of a history of ano-genital warts and pre-cancerous lesions or abnormal Pap/HPV tests $(8,9)$, in men or women not older than 26 years (86). Although a $\geq 1$ dose of HPV vaccination coverage increases notably each year, it is still much below the expected coverage of $91 \%$ by 13 years of age, due to missed vaccination opportunities/non-adequate efforts in promoting the advantages of reducing vaccinepreventable infections and cancers (11). Consequently, the Advisory Committee on Immunization Practices recommends administration of HPV vaccine at the same visit with other age-appropriate vaccines (11). Geographic variations of different HPV types have been reported by numerous studies on women with cervical lesions of various degrees of severity, including cervical cancer $(7,87,88)$ and should be taken into account when designing future HPV vaccination programs to prevent HPV-induced carcinogenesis (7).

\section{Proteomics technologies for the identification of markers}

Discoveries of proteomics biomarkers in HPV-related cancer. Given the expansion of proteomics studies and the advances brought by this strategy in the diagnosis, prognosis and therapy monitoring, proteomics have recently focused on HPV-related neoplasia (73). Oncogenic human DNA viruses, such as HPV, have co-evolved with their human hosts and studies of viral proteomics can identify important tumorigenic pathways, as well as novel therapeutic targets $(70,89)$. Nevertheless, there are still extensive gaps in proteomic knowledge related to HPV-related cancer forms, the difficulties due to the HPV prevalence and type distribution in women with HPV-related cancers other than cervical ones (27). The complexity of this group of diseases can be matched only by equally complex proteomic data $(29,30)$.

Several 'omic' fields have studied the associations with HPV-dependent cancer lesions. Wu et al examined the molecular pathogenesis of HPV-related oral cavity SCC and reported that there was a significant difference in the incidence of HPV type 16 infection-related and HPV-non-related cancer (90). Acknowledging that paxillin can promote lung tumor progression and that HPV type 16 E6 can reduce miR-218 expression in cervical cancer, the role of paxillin in oral cavity SCC was investigated. An increased capacity for invasion in HPV-infected cancer cells was found to be associated with paxillin expression. In tumor specimens with HPV type 16/18 infection, a negative association was observed with miR-218 expression. Moreover, a shorter relapse-free survival and overall survival was associated in patients with tumors with a low miR-218 and high paxillin expression. HPV-infected patients with tumors with a high paxillin and low miR-218 expression have the most unfavorable relapse-free and overall survival. There is evidence to indicate that targeting paxillin in order to suppress tumor progression/improve the clinical outcome of oral cavity SCC, particularly in HPV-infected patients, can lead to novel therapeutic regimes (90).

Proteomics analyses, expanding on the neoplastic differentiation of HPV-infected cells, have indicated that the E6-mediated ubiquitination of $\mathrm{p} 53$ is present in infections involving high-risk HPV types. A number of novel E6AP-interacting proteins have been detected and validated, among which the most important are NEURL4, HIF1AN and mitogen-activated protein kinase 6 (MAPK6) (91). E6AP comprises several different protein complexes, including an independent high-molecular-weight complex containing HECT and RLD domain containing E3 ubiquitin protein ligase 2 (HERC2), neuralized E3 ubiquitin 
protein ligase 4 (NEURL4) and MAPK6, as well as a proteasome (92). These proteomics studies revealed for first time the E6AP complexity and involvement in infections caused by high-risk HPV types (91).

Due to the small size of the HPV genome $(7-8 \mathrm{kbp}$, at most eight genes) the viral lifecycle requires these protein products to be able to execute multiple functions. Thus, E2 proteins play an important role in the HPV lifecycle. Specifically, the E2 proteins contain a conserved C-terminal DNA binding structure, a dimerization domain (90-100 amino acids) and a conserved N-terminal domain (200-210 amino acids) (92). The specific structural characteristics of the E2 proteins allow their involvement in viral transcription and replication; whereby they interact with host's proteins in order to fulfill the entire viral life cycle (84). E2 proteins aid viral replication by establishing links between regions of cellular chromatin under replication stress and viral replication foci (93).

In $\mathrm{HPV}^{+}$oropharyngeal cancer, proteomics markers, such as $E 2$ expression have been recently associated with $C D 8^{+}$ tumor-infiltrating lymphocyte counts, age and T-stage to predict progression-free survival and stratify patients for therapy (94). The high tumorigenic potential of HPV relies on the cell cycle deregulation/inhibition of p53-mediated apoptosis; both tumorigenic processes are induced by $E 6$ and $E 7$, the two main viral oncogenes. These viral oncogenes inactivate p53 and the retinoblastoma protein (24). Recently, the gamma HPV197 interactome investigation has indicated that the E6 protein interacts with a large number of cellular proteins, including the TP53 tumor suppressor that is thus inhibited. Although it seems that the HPV197 E7 structure would not accommodate the binding to retinoblastoma protein, it was demonstrated that it does and activates $E 2 F$ transcription (95).

Using several proteomic technologies, matrix-assisted laser desorption ionization time-of-flight mass spectrometry (MALDI-TOF-MS) and fluorescent two-dimensional electrophoresis, in cervical cancer, mimecan, actin from aortic smooth muscle and lumican were found to be overexpressed, while keratin, type II cytoskeletal 5, peroxiredoxin-1 and 14-3-3 protein sigma expression levels were found to be decreased (96). Moreover, using one dimensional electrophoresis, followed by direct mass spectrometry in SCC of the penis, several proteins were identified. $\mathrm{HPV}^{+}$penile $\mathrm{SCC}$ and $\mathrm{HPV}^{-}$non-tumorous penile foreskins were analyzed and 63 different proteins were revealed in the $\mathrm{HPV}^{+}$group. One of this complex array of proteins proved to be complement $\mathrm{C} 3$, which was useful in the evaluation of patients with penile SCC (97).

Protein microarray, an emergent proteomic technology (98), is gaining its place in proteomics. For the study of the diversity of oncogenic HPV types, a customized HPV protein microarray with 98 proteins in the form of C-terminal GST fusion proteins, has been recently developed. The utilized protein markers are representative of eight antigens of two low-risk HPV types (6 and 11) and 10 oncogenic high-risk HPV types $(16,18,31,33,35,39,45,51,52$ and 58) demonstrating a high reproducibility in human samples. Statistically significant IgG sero-reactivity for HPV16 E1, E2 and E7 was obtained in oropharyngeal carcinoma patients, validating prior ELISA results. That study is one of the first to emphasize the potential of using protein microarray assays in HPV-related cancer (99).
Genomic markers in HPV-related cancer. The majority of studies on HPV-related cancers have gathered genomic data. The following alterations have recently been highlighted: Amplifications of regions that comprise mainly oncogenes, deletions that comprise mainly genes involved in proliferation and cell cycle regulations, mutations and a rapidly expanding domain, DNA methylations. Using genomic technologies, in various human non-melanoma skin cancers, ten different HPVs were detected in $>50 \%$ of the tested samples. The reported genomic sequences comprised the known HPV types 16, 22, 120 and 124, two previously known putative types and four previously unknown HPV sequences. The most commonly detected virus was HPV197 in $>30 \%$ of all skin cancer samples (100).

In $\mathrm{HPV}^{+}$tonsillar carcinoma there is a marked enhancement of 3q24-27 amplifications, comprising PIK3CA, TP63, SOX2, CCNL1, PARP1, hTERC and DCUN1D1 oncogenes (101). $3 \mathrm{q}$ amplifications have also been found in the early stages of cervical cancer that progresses to more advanced stages (102). In earlier head and neck SCC studies, chromosomal aberrations in 7q, Xp, 8p, 11q22 (harboring the ATM gene), 13q, $14 q 32$ (harboring the TRAF3 gene), and 15q have also been reported (103). Recently, a subset of $\mathrm{HPV}^{+}$head and neck SCC harboring mutations in TRAF3 and $C Y L D$ have been reported, suggesting their involvement in HPV-related tumorigenesis (104). Moreover, gene loss (SMAD4), hinders TGFb signaling and favors uncontrolled cell proliferation and anti-apoptotic events in head and neck SCC (24).

The detection of mutations in $\mathrm{HPV}^{+}$lesions is a comprehensive research domain. $\operatorname{TpCp}(\mathrm{A} / \mathrm{C} / \mathrm{T})$ substitutions in the $A P O B E C 3 B$ cytosine deaminase gene altering the enzyme activity have been reported in both $\mathrm{HPV}^{+}$head and neck SCC and cervical cancers. $A P O B E C$ is associated with helical domain hot spot mutations in the PIK3CA gene detected in a number of neoplasms (105). Certain deregulated intracellular signaling pathways are caused by the increased frequency of mutations, such as the PI3K pathway (PIK3CA, PTEN, PIK3RI genes mutated) and the MAPK pathway (KRAS gene mutated). Using human xenografts expressing mutant $P I K 3 C A$ harvested from $\mathrm{HPV}^{+}$and $\mathrm{HPV}^{-}$head and neck SCC, it was demonstrated that $P I K 3 C A$ mutation status can be utilized as a target for $\mathrm{mTOR} / \mathrm{PI} 3 \mathrm{~K}$ inhibitors. Thus, in animals bearing xenografts with mTOR/PIK3CA inhibitors, an attenuated tumor growth was observed (106).

DNA methylation is another genomic domain that is highlighted in the characterization of $\mathrm{HPV}^{+}$head and neck SCC. Thus, the profile identification of global DNA methylation proves that $\mathrm{HPV}^{+}$head and neck SCC tissues display increased hyper methylation compared to $\mathrm{HPV}^{-}$tumors (107). Global hypermethylation is possibly induced by E6 ectopic expression, thus E6 is suggested as the primary methylation factor. Epigenetic silencing in $\mathrm{HPV}^{+}$head and neck SCC can modulate gene families involved in proliferation and cell cycle regulation. The hypermethylation of the cadherin gene family has been shown to induce HPV-mediated tumorigenic progression through epithelial-mesenchymal transition (108). Moreover, it was recently reported, that in $\mathrm{HPV}^{+}$head and neck SCC, long non-coding RNAs (lncRNAs) cluster in five distinct tumor regions and are associated with DNA methylation and TP53 mutation, as shown by RNAseq expression data. 


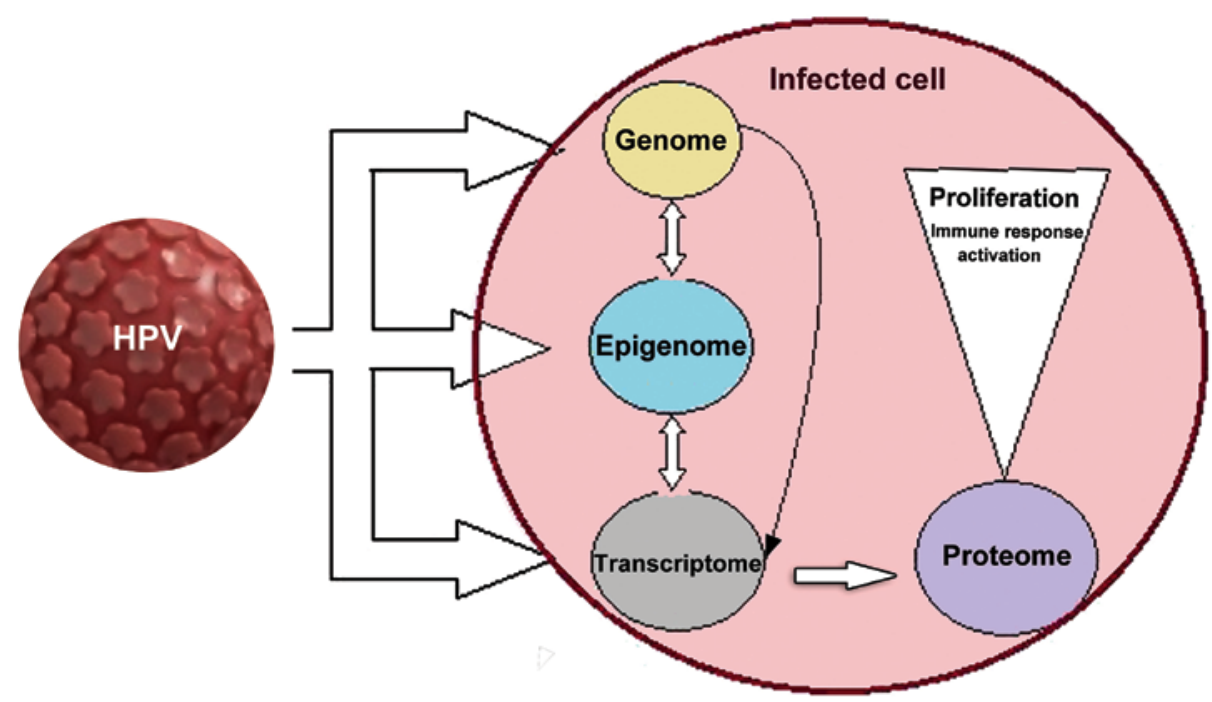

Figure 1. An HPV-infected cell is subjected to multiple transformations. HPV infects initially actively dividing basal epithelial cells. HPV then integrates into the host genome inducing specific alterations of host cellular gene expression. The expression of high-risk HPV E6/E7 proteins augments genomic instability and induces epigenetic and further transcriptomic alterations that generate proteins (proteome) that maintain a host cellular milieu favorable to viral genome replication. The altered infected cell develops modified intracellular events that induce aberrant proliferation and further generate immune response activation. On all altered levels, beginning from HPV insertion into the host cell genome, through epigenetic alteration and the transcription of altered proteins, biomarkers indicative of HPV infection can be identified. HPV, human papilloma virus.

Importantly, this lncRNA reported clustering correlates with patient survival and tumor grade (109).

In terms of therapy, $\mathrm{HPV}^{+}$tumor responsiveness to radiotherapy can be increased by the activating amyloid precursor protein binding protein-1 gene (APP-BPI), as through this mechanism, the upregulation of p53-mediated apoptosis can be further induced $(110,111)$. Therefore, gene therapy aiming at restoring wild-type $p 53$ expression may prove to be a novel therapeutical route in head and neck SCC $(102,112)$. Another possible therapeutical approach focuses on the epigenetic field, where the hypermethylation of the SMG1 promoter appears to increase $\mathrm{HPV}^{+}$head and neck SCC cell line sensitivity to radiation (113). As shown in a separate study, the promoter methylation signature of five genes, ALDH1A2low, OSR2low, GATA4high, GRIAlhigh and IRX4high, may be utilized as a prognostic marker. These methylation signatures can identify specific treatment-responsive patients in oropharyngeal cancer (114). It is important to highlight that the HPV head and neck SCC genetic pattern differs significantly from the $\mathrm{HPV}^{+}$one. Thus, a loss of the 17q/mutation of TP53 and of the 9 p/inactivation has been reported (103), along with amplification at locus 11q13 (the site harboring $C C N D 1$ oncogene, $C T T N$ and FADD genes) (25). The loss of $16 q 12-24$, as well as FGFRI amplifications (114), seems to be specific to HPV head and neck SCC (110). Of note, EGFR gene amplifications localized at chromosome $7 \mathrm{p}$, have been found to be present in $>13 \%$ of HPV $^{-}$head and neck SCC (114). In brief, genomic markers for $\mathrm{HPV}^{+}$and HPV head and neck SCC are summarized in Table II.

An overview of the 'omics' biomarkers related to HPV infection is presented in Fig. 1. On all altered levels, beginning from HPV insertion into the host cell genome, through epigenetic alteration and the transcription of altered proteins, biomarkers indicative of HPV infection can be identified.

Use of proteomics technologies for biomarker identification. To date, major markers able to assist effective therapy have been identified, However, further steps along this path, are the study of interactions between the host and the virus in order to improve disease outcomes and, more concretely, for the development of biomarkers able to perform the accurate triage of patients with HPV infection.

Against the increasingly confirmed knowledge that cancer may begin from proliferative cancer stem cells of high tumorigenic potential, to which the information is added related to the capacity of other oncogenic viruses to induce stem cell-associated gene expression, a study researched the possibility to detect, on the one hand, the presence of mRNA or proteins from stem cell associated genes and/or increased cell proliferation, and on the other hand, in appropriate current cervical-vaginal fluid samples from high risk $\mathrm{HPV}^{+}$women. The use of cervical-vaginal fluid samples has demonstrated benefits as a biomarker source for lower female reproductive system pathologies, due to easy collection, with the prospective of utilizing self-tests. The following detection methods have been used, to date, for this sample examination: RT-qPCR for mRNA, flow cytometry and antibody-based proteomic microarray for stem cell-associated genes and flow cytometry for increased cell proliferation (121).

The study material also included cytological and histological sample results, indicating moderate-high abnormality rates. In samples from patients with CIN3, respective analysis revealed upregulated stem cell-associated proteins (e.g., the oncogene TP63, human chorionic gonadotropin) and the SOX2 transcription factor. Moreover, certain samples collected from a subset of this patient group, the stem cell-related, surface podocalyxin protein could be detected. In high-grade disease samples, SOX2, TP63 and human gonadotrophin mRNAs were upregulated. Immunohistochemistry experiments performed revealed that SOX2 and TP63 proteins visibly outlined tumor cells in invasive forms of squamous cervical cancer (121).

A different study envisaged the identification of a cervical-vaginal fluid protein biomarker indicative of cervical cancer or its respective pre-cancer stage. The study involved 
Table II. Markers in $\mathrm{HPV}^{+}$and HPV ${ }^{-}$head and neck SCCs.

$\mathrm{A}, \mathrm{HPV}^{+}$head and neck SCCs

\begin{tabular}{|c|c|c|c|c|c|c|c|}
\hline \multicolumn{2}{|c|}{ Marker } & \multirow[b]{2}{*}{ Chromosome } & \multirow[b]{2}{*}{ Genetic } & \multirow[b]{2}{*}{ Epigenetic } & \multirow[b]{2}{*}{ Trans-criptomic } & \multirow[b]{2}{*}{ Proteomic } & \multirow[b]{2}{*}{ (Refs.) } \\
\hline Family member & Type & & & & & & \\
\hline $\begin{array}{l}\text { Receptor tyrosine } \\
\text { kinases }\end{array}$ & FGFR2/3 & & $\begin{array}{l}\text { Mutation/ } \\
\text { amplification }\end{array}$ & & & & $(112)$ \\
\hline \multirow[t]{2}{*}{ PI3K pathway } & PIK3CA & $3 q 26$ & Mutation & & Upregulated & & $(112)$ \\
\hline & PIK3R1 & & Mutation & & & & $(112)$ \\
\hline MAPK pathway & KRAS & & Mutation & & & & (112) \\
\hline TGFb pathway & SMAD4 & $18 \mathrm{q} 21$ & Loss & & & & $(112)$ \\
\hline \multirow[t]{6}{*}{ Cell cycle } & $\mathrm{E} 2 \mathrm{~F} 1$ & $20 q$ & Amplification & & & & $(112)$ \\
\hline & E2F targets ${ }^{a}$ & & & & Upregulated & Upregulated & $(115)$ \\
\hline & PCNA & & & & Upregulated & Upregulated & $(115)$ \\
\hline & APP-BP1 & $16 q 22$ & Loss & & Downregulated & & $(116)$ \\
\hline & miR family ${ }^{b}$ & & & & Upregulated & & (116) \\
\hline & miR family ${ }^{c}$ & & & & Downregulated & & (116) \\
\hline \multirow[t]{8}{*}{ Immune response } & TRAF3 & $14 q 32$ & Loss & & & & $(112)$ \\
\hline & $\begin{array}{l}\text { IFN-induced } \\
\text { genes }^{\text {d }}\end{array}$ & & & & Downregulated & & (117) \\
\hline & IL6 & & & & & Downregulated & $(117)$ \\
\hline & IL10 & & & & Downregulated & & $(117)$ \\
\hline & IL13 & & & & Downregulated & & $(117)$ \\
\hline & Immunoglobulins & & & & & Downregulated & $(117)$ \\
\hline & Lactotransferrins & & & & & Downregulated & $(117)$ \\
\hline & $\begin{array}{l}\text { Lymphocyte } \\
\text { activation induced }^{\mathrm{e}}\end{array}$ & & & & Upregulated & & (117) \\
\hline $\begin{array}{l}\text { JAK-STAT } \\
\text { pathway }\end{array}$ & JAK3, STAT5A & & & $\begin{array}{l}\text { Promoter } \\
\text { methylated }\end{array}$ & & & $(118)$ \\
\hline EMT & $\begin{array}{l}\text { Cadherin } \\
\text { family members }\end{array}$ & & & $\begin{array}{l}\text { Promoter } \\
\text { methylated }\end{array}$ & & & $(118)$ \\
\hline \multirow{3}{*}{$\begin{array}{l}\text { Tissue } \\
\text { development and } \\
\text { regeneration }\end{array}$} & GATA4 & & & $\begin{array}{l}\text { Promoter } \\
\text { methylated }\end{array}$ & & & $(118)$ \\
\hline & GRIA1 & & & $\begin{array}{l}\text { Promoter } \\
\text { methylated }\end{array}$ & & & $(118)$ \\
\hline & IRX4 & & & $\begin{array}{l}\text { Promoter } \\
\text { methylated }\end{array}$ & & & $(118)$ \\
\hline \multirow{5}{*}{$\begin{array}{l}\text { DNA repair } \\
\text { or recombination }\end{array}$} & ATM & $11 q 22$ & Loss & & & & $(112)$ \\
\hline & BRCA1/2 & & Mutated & & & & $(112)$ \\
\hline & $\begin{array}{l}\text { Testis-specific } \\
\text { genes }^{\mathrm{g}}\end{array}$ & & & & Upregulated & & $(112)$ \\
\hline & SMG1 & & & $\begin{array}{l}\text { Promoter } \\
\text { methylated }\end{array}$ & & & $(112)$ \\
\hline & miR-363 & & & & Upregulated & & (116) \\
\hline
\end{tabular}


Table II. Continued.

$\mathrm{B}, \mathrm{HPV}^{-}$head and neck SCCs

\begin{tabular}{|c|c|c|c|c|c|c|c|}
\hline \multicolumn{2}{|c|}{ Marker } & \multirow[b]{2}{*}{ Chromosome } & \multirow[b]{2}{*}{ Genetic } & \multirow[b]{2}{*}{ Epigenetic } & \multirow[b]{2}{*}{ Trans-criptomic } & \multirow[b]{2}{*}{ Proteomic } & \multirow[b]{2}{*}{ (Refs.) } \\
\hline Family member & Type & & & & & & \\
\hline Receptor tyrosine & EGFR & $7 \mathrm{p} 12$ & Amplification & & & & $(103,112)$ \\
\hline kinases & FGFR1 & $8 p 11$ & $\begin{array}{l}\text { Mutation/ } \\
\text { amplification }\end{array}$ & & & & \\
\hline MAPK pathway & HRAS & & Mutation & & & & $(103,112)$ \\
\hline TGFb pathway & SMAD4 & $18 \mathrm{q} 21$ & Amplification & & & & $(103,112)$ \\
\hline \multirow[t]{5}{*}{ Cell cycle } & TP53 & & Mutation & & & & $(103,112)$ \\
\hline & CCND1 & $11 \mathrm{q} 13$ & Amplification & & Upregulated & & $(103,112)$ \\
\hline & CDKN2A & $9 \mathrm{p} 21$ & $\begin{array}{l}\text { Loss/ } \\
\text { mutation }\end{array}$ & $\begin{array}{l}\text { Promoter } \\
\text { methylated }\end{array}$ & Downregulated & Downregulated & (115) \\
\hline & RASSF1A & $3 p$ & Loss & & & & (119) \\
\hline & FHIT & $3 p$ & Loss & & & & (119) \\
\hline \multirow{4}{*}{$\begin{array}{l}\text { Tissue } \\
\text { development and } \\
\text { regeneration }\end{array}$} & ALDH1A2 & & & $\begin{array}{l}\text { Promoter } \\
\text { methylated }\end{array}$ & & & (107) \\
\hline & OSR2 & & & $\begin{array}{l}\text { Promoter } \\
\text { methylated }\end{array}$ & & & (107) \\
\hline & FADD & $11 \mathrm{q} 13$ & Amplification & & & & $(120)$ \\
\hline & CTTN & $11 \mathrm{q} 13$ & Amplification & & Upregulated & Upregulated & $(120)$ \\
\hline
\end{tabular}

${ }^{\mathrm{a} M C M s}$, CDC2/7, CCNA1 and CCNE1; ${ }^{\mathrm{b}} \mathrm{miR}-15 \mathrm{a}$ and miR-16; ${ }^{\mathrm{c}} \mathrm{miR}-195$, miR-424 and miR-497; ${ }^{\mathrm{d}}$ IFIT1, IFITM1-3, IFI6-16 and OAS2; ${ }^{\mathrm{e}} \mathrm{HLA}-\mathrm{DRA}, \mathrm{HLA}-\mathrm{DRB} 1 / 3 / 5, \mathrm{CSK}$ and ICAM1; ${ }_{\mathrm{f}} \mathrm{CDH} 8 / 15$, PCDH8-10 and PCDHB3; ' $\mathrm{SYCP} 2, \mathrm{TCAM} 1$ and STAG3. HPV, human papilloma virus; SCC, squamous cell carcinoma.

a differential proteomics approach applied to cervical-vaginal fluid samples collected from healthy patients or women at pre-cancer stages. The quantification of protein expression was performed by label-free spectral counting and proteome analysis (122). This approach identified 16 candidate biomarkers, the most promising of which were alpha-actinin-4 and pyruvate kinase isozyme M1/M2. ELISA applied to alpha-actinin-4 demonstrated the potential of this candidate biomarker to distinguish between healthy samples and both low- and high-risk HPV-infected patients. By further analysis of longitudinal samples, the correlation between levels of alpha-actinin-4, on one hand, and viral clearing and persistence, on the other hand, were demonstrated, allowing for $18 \mathrm{pg} / \mathrm{ml}$ levels as discrimination frame (122).

A separate study utilizing a quantitative proteomics-based approach compared the protein expression profiles in two $\mathrm{HPV}^{+}$ head and neck cancer cell lines and one HPV ${ }^{-}$head and neck cancer cell line, leading to the identification of 155 differently expressed proteins. In the $\mathrm{HPV}^{+}$cell lines, prostate stem cell antigen (PSCA) was upregulated, whereas the eukaryotic elongation factor 1 alpha was downregulated, the statuses of which were confirmed by immunofluorescence and western blot analyses. In addition, in two clinical series of $\mathrm{HPV}^{+}$and $\mathrm{HPV}^{-}$oral cavity carcinoma cases, differences were shown between PSCA and eukaryotic elongation factor 1 alpha expression levels (123). The study accordingly led to a first-time demonstration of the association between the $\mathrm{HPV}^{-}$status and the PSCA and eukaryotic elongation factor 1 alpha, indicative of the likelihood of the involvement of these proteins in carcinogenesis associated with HPV infection (123).

Expanding the use of monoclonal antibodies in several domains, was one of the proteomics approaches with intense development in new treatments for head and neck cancer. Thus, cetuximab, a monoclonal antibody inhibitor of epidermal growth factor receptor, was evaluated in comparison with radiotherapy in an international randomized trial for assessing the best therapeutic regimen in loco-regionally advanced SCC of the head and neck (124). This innovative approach simultaneously used cetuximab and high-dose radiotherapy for the loco-regional control of the tumors and induced an important lifetime prolongation (49 vs. 29.3 months for radiotherapy alone), without increasing the toxic effects related to radiotherapy (124). Another recently developed monoclonal antibody against the thrombin-sensitive site of the osteopontin molecule was used to test osteopontin as a possible circulating biomarker in cervical cancers. In both serum and plasma, the osteopontin level was significantly higher compared to healthy subjects, and was reported as having the highest values in stage III-IV. 
However, as osteopontin can exist in a truncated form and thus, the target epitope recognized by the monoclonal antibody may be absent, further studies are warranted to investigate the mechanisms through which the entire molecule and/or its fragments play a role in cervical cancer biology (125).

Proteomics may aid in the elucidatation of a certain status of the HPV-infected milieu. For instance, in cervical cancer, oxidative stress can be considered as an insufficiently exploited factor as regards its role in HPV-initiated carcinogenesis. Along these lines, complex proteomic and imagistic approaches were used to investigate certain proteins involved in the overall redox status in HPV type 16-positive tissues. Thus, tissue samples from patients with invasive squamous cervical carcinoma, dysplastic HPV lesions and controls, were assessed for the expression levels of stress markers, such as endoplasmic reticulum protein 57 (ERp-57), glutathione S-transferase (GST), inducible nitric oxide synthase (i-NOS), as well as thioredoxin reductase 2 (TrxR2) levels. In addition, chemical modifications (carboxylation and oxidation) were evaluated in some key proteins recognized for their role in cytoskeletal structure maintenance and cell differentiation. Hence, a HPV tissue pattern I was registered for each type of lesion. Specifically, in dysplastic lesions, ERp57 and GST were highly elevated, whereas TrxR2 and iNOS were gradually decreased; other factors, such as cytokeratin 6, actin, cornulin, retinal dehydrogenase and GAPDH were found to be highly carbonylated in comparison with the controls (126). The results of the carboxylation degree could account for protein function failure, providing hints as to the involvement of stress-related molecular mechanisms in tumor development. For neoplastic lesions, ERp57 and GST were also found to be elevated, while at the same time reduced levels of iNOS were determined (126). Indeed, the assessment of chemical modification indicated that peptidyl-prolyl cis-trans isomerase A, ERp57, serpin B3, Annexin 2 and GAPDH were found to be less oxidized in normal as compared with dysplastic tissues. Furthermore, it was suggested that HPV type 16e neoplastic progression may be related to a pro-oxidant environment. However, the oxidative damage seems to be tightly controlled by tumor cells, as indicated by the selective reduction of carboxylation on key pro-survival proteins (e.g. ERp57, Serpin B3 and GAPDH), thus underlining another defense mechanism initiated by the tumor cells (126). The link between oxidative stress, UVB radiation and HPV infection were assessed in a study where a parallel proteomic approach analyzed the expression pattern and oxidative alterations of proteins in a HPV type 16-transformed keratinocytes (HK-168) cells following UVB exposure. Protein expression profiles assessed 21 proteins displaying differential expression levels in cells exposed to UVB radiation in comparison with unexposed cells. Furthermore, UVB treatment revealed five proteins highly carbonylated namely: Alpha-enolase, heat shock protein 75 , Annexin 2, elongation factor Tu and elongation factor gamma. Therefore, proteomics approaches in this case suggested that UVB-induced oxidative stress triggers a carbonylated state of specific proteins, which when combined with the detected protein modifications in HPV-transformed keratinocytes may contribute to malignant progression (127).

Hypoxia has also been suggested as a factor that enhances tumor development and metastasis (128). In some pathologies, the determination of clinically relevant hypoxia may be used to classify patients who will benefit from the adjustment of the hypoxia level during the radiotherapy regimen. It was shown that the osteopontin level in plasma was associated with tumor hypoxia. Indeed, in patients with head and neck cancer, the higher the plasma osteopontin concentration, the poorer the outcome after radiotherapy. This disadvantage may be resolved by a hypoxia radiosensitiser nimorazole, as in the case of the DAHANCA 5 trial, which established that nimorazole significantly improved the outcome of patients subjected to radiotherapy when compared to placebo (128). Recently, a group of 63 patients with head and neck SCC was tested in the DAHANCA-5 trial, where the plasma levels of nimorazole were analyzed by high pressure liquid chromatography (HPLC). The HPLC data revealed a linear correlation between the peak plasma level and dose, the mean peak concentration was $32.2 \pm 0.9 \mu \mathrm{g} / \mathrm{ml}$, the median time of peak concentration was $60 \mathrm{~min}$ and the mean half-life was $3.35 \pm 0.09 \mathrm{~h}$. Of note, a statistically significantly longer nimorazole half-life in men compared with women was registered. Overall, this study that used the HPLC approach may provide a nimorazole scheme forecast in patients, with nimorazole being generally well tolerated (129).

Proteomics approaches have also provided insight related to the cell status upon viral infection. For instance, 2-D electrophoresis and MALDI-TOF technology were performed in a study to elucidate the pattern of interactions between some viral oncogenes expressed in cells infected with HPV type 16 and proteins related to cell signaling, apoptosis and cell cycle regulation. The HaCaT keratinocyte cell line was induced to stably express E7, encoded by one of the viral oncogenes selectively expressed in carcinoma cells upon HPV type 16 infection. Proteomics data revealed that $>20$ important factors are modulated by E7, being downregulated (e.g., leukocyte elastase inhibitor) or upregulated (heat shock $60 \mathrm{kDa}$ protein, catalase and peroxiredoxin 2), thus influencing cell signaling, apoptosis or cell cycle processes (130).

Studies on HPV type 16 have been continued with integrative proteomics approaches linked to E6 oncoproteins and their targets; E6 from high-risk mucosotropic HPV types can trigger the degradation of the p53 tumor suppressor and the apoptosis-inducing Bak protein, through the interaction with the E6AP ubiquitin-protein ligase. On the contrary, E6 from low-risk mucosotropic HPV types interacts in a lower affinity manner with E6AP, but the target proteins are still unknown (131). Additionally, this E6 type, unlike cutaneous E6 proteins, can induce the degradation of proteins containing PDZ-binding domain. Importantly, that study could define the differences and similarities of how HPV-related mucosal and cutaneous E6 proteins interact with intracellular targets, such as cellular ubiquitin-protein ligases (131).

Comprehensive tumor profiling was used for the study of a possible link between HPV infection and relapse risk in vulvar SCC (VSCC), which befall in two distinct subtypes, one related to high-risk HPV and one negative for HPV, both acknowledged to develop through distinct intracellular signaling pathways. A number of 14 VSCC tumor proteome specimens were analyzed by liquid-chromatography tandem mass spectrometry followed by complex protein quantification techniques, the fractionation of labeled peptides by high-resolution isoelectric focusing and liquid-chromatography tandem mass spectrometry. As a result of such complex proteomic inquires, 1,579 proteins 
were quantified and further analyzed, in a novel approach, for generating individual tumor pathway alteration data, HPV multivariate statistics and relapse status comparisons. Thus, 4 proteins identified as main classifiers of relapse grade were validated by immunohistochemistry, two of which were found to be interferon-regulated and HPV-repressed at the mRNA level. Further, liquid-chromatography tandem mass spectrometry and immunohistochemistry identified a subgroup of HPV negative/relapse-associated tumors. The ubiquitin-proteasome pathway was further identified to be altered in the high risk subgroup (132).

A correlation between tumor biology and clinical consequences dictated by HPV subtype infection is likewise a challenge in the case of oropharyngeal carcinoma. Through a standardized global proteomic analysis platform, 2,653 proteins were identified, out of which 31 were selected on the basis of expression differences between $\mathrm{HPV}^{+}, \mathrm{HPV}^{-}$and normal epithelium. The emerging protein pattern registered an involvement of proteins associated with epithelial cell development, keratinization and extracellular matrix organization in $\mathrm{HPV}^{-}$, while for $\mathrm{HPV}^{+}$tumors the results indicated a profile of proteins involved in DNA initiation, replication and the cell cycle. Tissue microarray also identified differences in terms of transcription factors and essential amino acid dependency based on the presence of HPV, contributing to deciphering molecular pathways for $\mathrm{HPV}^{+} / \mathrm{HPV}^{-}$oropharyngeal carcinoma suitable for therapy and disease monitoring (117).

\section{HPV markers}

Understanding the structure of HPV and the biology of its infection was difficult until the 1990s, when the first virus propagation in organotypic cultures was produced, leading to the discovery of the genomic sequences. Even if, the latest molecular studies have provided a coherent mechanism of the HPV gene expression and replications, there are still unanswered questions regarding the HPV biology (133).

The eight reading frames of each DNA strand are divided into three parts: The $L$ (late) region responsible for the codification of structural proteins L1-L2, which are implicated in the virion assembly; the $E$ (early) region that encodes proteins E1-E7, which are involved in viral replications; and the $L C R$ necessary for the DNA transcription and replication $(77,134,135)$. Each papillomaviruses protein has specific characteristics, and is designed to support a specific genetic role. Thus, E1 is a viral protein with a size of $72 \mathrm{kDa}$ and is involved in viral replication. This viral protein binds to a specific DNA sequence and through the E2 viral protein, it assembles into hexameric complexes. This complex formation is responsible for the initiation of the DNA unwinding that produces subsequent synthesis of progeny DNA (77). E2 is responsible for viral gene transcription; therefore, low levels of this protein will activate transcription from the viral LCR, while high levels of E2 act as a transcriptional repressor. E2 is also involved in DNA replication. E4 is associated with viral assembly and release, but also with inducing the G2 arrest and distinguishing the nuclear domain 10. Importantly, this protein is active in the late part of the viral life cycle. E5 is implicated in inducing unscheduled cell proliferation, it activates the protein kinases and growth factor signaling, but it also inhibits cell apoptosis and the circulation of major histocompatibility complexes to the surface of cells (77). The E6 viral protein plays a role in inducing DNA synthesis, telomerase activity, cell polarity and motility, as well as in the regulation of transcriptional co-activators and tumor suppressors together with E7. The last papillomavirus protein is implicated in unscheduled cell proliferation and interacts with both negative regulators of the cell cycle and with histone acetyl transferases (77). As regards the late structural protein, L1 (major viral structural protein) and L2 (minor viral structural protein), they are involved in encoding neutralizing epitopes, but also in assembling the capsomers and the capsid. Indeed, these proteins interact interact with other cell receptors) and facilitate virion assembly, interacting with both DNA and nuclear domain 10 (L2).

Importantly, HPV proteins are useful as markers. The past or present HPV infections can be confirmed after a serious epidemiological research, the antibody response to the HPV capsid being a predictable marker for the cumulative exposure to HPV. The cervical or oropharyngeal HPV-induced cancers are characterized by the presence of E6 (the main viral effector E6 gene) and E7 antibodies (108). The development of SCC is produced by genetic alterations, such as mutations and copy number alterations at the level of DNA, but also by epigenetic changes characterized by the aberrant methylation and histone genetic modifications (90).

However, even if the E6 and E7 proteins antibodies are markers for HPV type 16- and 18-induced cancer, not all patients with malignant oropharyngeal disease express these antibodies, and thus they cannot be used as diagnostic markers (137). There are epidemiological studies in progress, in order to further examine the correlation between HPV-induced cancer and the presence of E6 and E7 proteins antibodies by either peptide ELISA or western blot analysis (130). Other researches have indicated that there is a correlation between cervical cancer and the presence of E2 and E4 antibodies or some specific linear sequences of these proteins (138).

HPV type 16 is considered to be the most prevalent viral genotype implicated in head and neck SCCs. Studies have suggested that SCC associated with HPV DNA positive/RNA positive has a better survival expectation in comparison to carcinomas induced by HPV DNA-positive/RNA-negative or HPV-negative malignant tumor $(137,138)$. Head and neck cancers induced by HPV have an HPV-mediated DNA methylation in tumor cells (107). DNA methylation is an epigenetic mechanism that is characterized by the addition of methyl (CH3) to cytosine. This process is an important regulator of gene transcription being controlled by an enzyme family known as DNA methyltransferases (DNMTs). Furthermore, hypermethylation is most predominant at the level of TSS 200 promoter regions, but also at the gene bodies, both of these being good markers of gene silencing. It is well known that an important role in cellular transformation is played by the hypermethylation of the promoter region of tumor suppressor genes (107).

There are data available that have correlated serine/ threonine-protein kinase SMG-1 (involved in both mRNA surveillance and genotoxic stress response pathways) with oropharyngeal SCC. SMG-1 is underexpressed in HPV-positive head and neck cancers in comparison with HPV-negative ones. It has been demonstrated that HPV type 16 E6 and E7 induce $S M G-1$ promoter hypermethylation (113). Other tumor 
suppressor genes implicated in carcinogenesis and hypermethylation are various cadherin subtypes, such as E-cadherin $(C D H 1)$, T-cadherin $(C D H 13)$ and proto-cadherin 10 (PCDH10) (108). Recent studies had indicated the involvement of $C D H 8$ and $C D H 13$, both determined to be hypermethylated in cervical cancer, in HPV-induced SCCs together with $C D H 18$, CDH19, CDH23, PCDH10, PCDH15, PCDHB1, PCDHB4 and $P C D H B 15$ (108). Specifically, the expression and methylation status of $C D H 8, P C D H 10$ and $P C D H B 11$ can potentially be used to discriminate between $\mathrm{HPV}^{+}$and $\mathrm{HPV}^{-}$induced $\mathrm{SCC}$, as well as in establishing a precise treatment response and in evaluating the evolution of the disease (108). Moreover, a decreased E-cadherin expression and subsequent impaired immune response is also related to HPV infections (108).

$C D K N 2 A$ or cyclin-dependent kinase inhibitor $2 \mathrm{~A}$ is a gene located at chromosome 9, band p21.3. It codes for two proteins, among which INK 4 family member p16 (p16 INK4a) and p14arf have been annotated the roles of tumor suppressors. This kinase was found to be overexpressed in carcinomas induced by HPV and to be reduced in HPV-negative tumors. There is evidence of a strong correlation between increased levels of HPV E6/E7 transcripts with significant viral loads and high expression levels of $C D K N 2 A$ (p16INK4A). SCCs $\mathrm{HPV}^{+}$can be the result of a $C D K N 2 A$ promoter hypermethylation and/or loss of $9 \mathrm{p} 21$. Of note, $C D K N 2 A$ is the second most commonly activated gene in carcinogenesis after p53 (110). Furthermore, the expression of genes $C D K N 2 A, C D K N 2 B$ and $C D K N 2 C$ was also associated with $\mathrm{HPV}^{+}$malignant tumors together with genes involved in the cell-based immune response (CXCL, CXCL11 and $I L-19)(110,112)$.

Another potential biomarker in HPV infection-related carcinomas may be the mitochondrial DNA of the patient. Thus, it has been shown that a large number of patients suffering from head and neck SCC had mitochondrial DNA mutations (139). The association between HPV infection and the mutagenesis of mitochondrial DNA is currently under investigation. Of note, the quantitative determination of mitochondrial DNA has proven to be a valuable indicator of local recurrence and distant metastases in SCC $(135,140)$.

Another line of research has demonstrated that there are connections between HPV-induced cancer and HPV chromosomal alterations, such as gains at 20p13-q13.33 and losses at 13q21.1-21.33. On the other side, lost regions at $3 p$ and $5 \mathrm{q}$ together with amplifications at $11 \mathrm{q} 13.3$ were common in HPV-negative carcinomas and absent in HPV-induced tumors. Indeed, these low level gains of chromosome 20q can be produced by E7 expression and the consequent inactivation of the retinoblastoma protein pathway in epithelial cells (120). Furthermore, head and neck tumors, but also cervical and anal carcinomas induced by HPV may be associated with the deletion of part of the long arm of chromosome 13 (120).

Some researchers have demonstrated the presence of specific genes at $20 \mathrm{q}$ and $13 \mathrm{q}$ chromosomes, underlying the importance of these related genes in HPV-mediated carcinogenesis. Indeed, they seem to be associated with continuous E7-regulated E2F1 activation, determining changes in cellular maintenance systems (nucleic acid metabolism). Furthermore, at the level of $20 \mathrm{q}$ region, cancer-related genes, such as $E 2 F 1$, $P I G U$ (phosphatidylinositol glycan anchor biosynthesis, class U-involved in cell cycle control and associated with bladder cancer) and DNMT3B (DNA cytosine 5-methyltransferase 3 beta) which is a de novo DNA methyl transferase (involved in cervical cancer) have been localized (120). There are also gains at $3 \mathrm{q}$ and losses at $11 \mathrm{q}$ associated with epithelial SCCs (120). PPFIA1, DHCR7, CTTN, TMEM16A and GAL genes are located in the $11 \mathrm{q} 13$ region which is affected in HPV-related tumors. For this reason, their expression in $\mathrm{HPV}^{+}$ carcinomas is decreased together with MAGEA4, MAGEA12 and $H M G A 2$ (120). As regards the detection of HPV capsid antibody, it was demonstrated that with the exception of HPV type 6, which contains shared epitopes and type-specific epitopes on intact capsids, conformationally dependent epitopes on intact capsids are HPV-type specific $(136,153)$.

\section{HPV treatment and cancer}

The treatment of head and neck SCC caused by HPV infection depends on the presence or absence of the HPV load in the tumors. It is considered that in the case of HPV-negative tumors, the prognosis is better as compared to that in HPV-positive ones, where the treatment is focused on improving the quality of life and the survival rate of patients (141). The treatment is specific according to the type and stage of the tumor. In the case of SCC and depending on tumor spread surgical resection of the tumor, chemotherapy, as well as radiotherapy may be necessary. For stage one and two tumors, external or internal radiotherapy is used as an elective treatment. Aggressive carcinomas can sometimes mimic benign lesions, but follow-up during evolution, as well as a poor response to treatment eventually characterize their biological behavior (142). As regards stage three and four tumors, the standard treatment is platinum salt chemotherapy combined with radiotherapy (143). In advanced forms of cancers, former platinum-based and fluorouracil regimens have been replaced with combinations of cetuximab and platinum salts that have demonstrated their superior efficacy (144).

Cervical cancer remains the most widespread form of cancer induced by the HPV virus and the fourth most common type of malignancy affecting females. There is no proper treatment of genital HPV infection. In the majority of women, the infection heals alone due to immune system activity. The treatments available for HPV genital infection are targeted at changes in the skin and mucosa caused by HPV infection such as condylomas, pre-cancerous lesions in the cervix or cervical cancer. Pre-cancerous lesions that bleed may over-infect with pathogenic germs (145) or fungus (Aspergillus or Fusarium genus) (146) which are difficult to treat. As alternative adjuvant therapy, various chemical compounds with anti-bacterial and anti-proliferative effects $(147,148)$ or plant extracts with cytotoxic and apoptotic effects may be administered (149). All of these therapeutic methods can remove the lesions, but do not remove the virus from the body. It can be eliminated exclusively by the action of the immune system. As the virus persists in the body, condylomas often relapse following treatment. Since the discovery of HPV, a need to formulate a vaccine to prevent infection and, subsequently, the development of cancer has existed. The vaccine mimics the disease and creates resistance. It is not a live virus or inactivated virus vaccine and thus it does not represent any risk for the individuals that use it (150). 


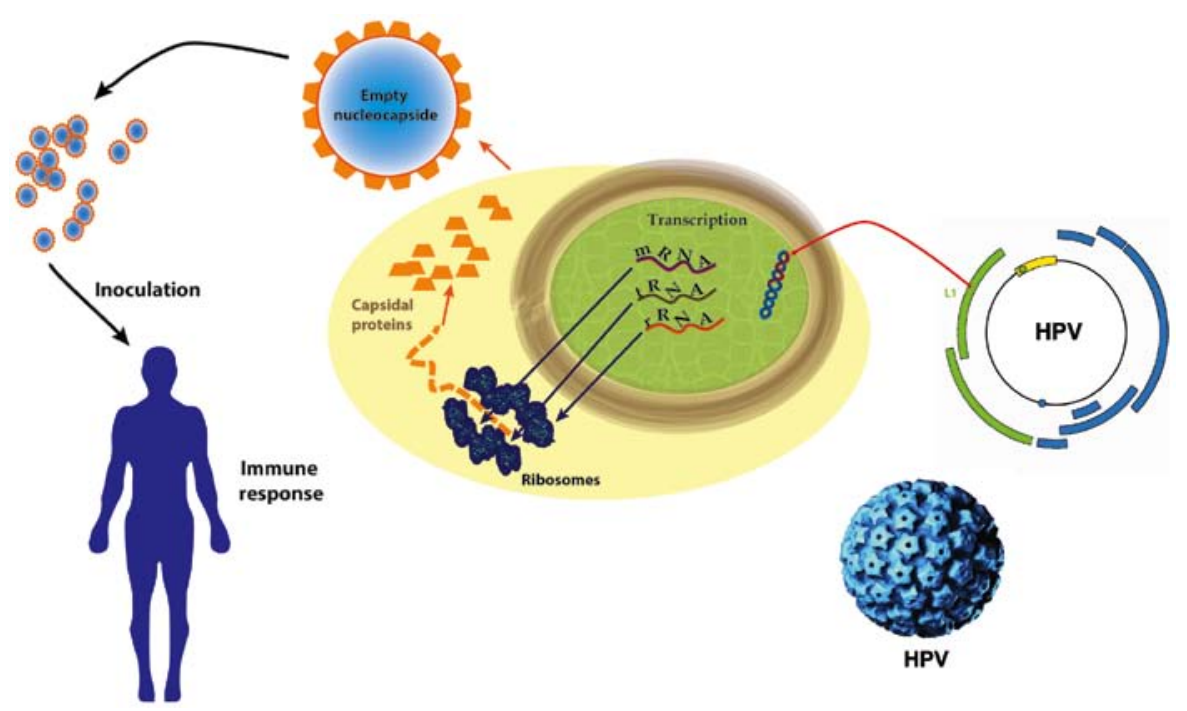

Figure 2. The mechanisms of action of HPV vaccines. HPV, human papilloma virus; mRNA, messenger ribonucleic acid; tRNA, transfer ribonucleic acid; rRNA, ribosomal ribonucleic acid.

The antipapillomavirus vaccines. In natural infection, HPV stimulates both humoral immunity (mediated by monoclonal antibodies), as well as cell-mediated immunity (mediated by T lymphocytes) in the human body. The body synthesizes antibodies to surface proteins L1 and L2; however, the intensity of the immune response varies from individual to individual and depends on the HPV type that causes the infection and on its persistence. Thus, the development of anti-HPV vaccines began after careful observations as to how the human body reacts as a result of infection with HPV (150). Studies on the vaccines began in the 1980s, and the results materialized only in 2006, when the two vaccines containing L1 viral proteins produced by genetic recombination techniques appeared. The proteins are assembled into morphologically similar particles to the viral, but do not contain the genome (DNA-viral double-stranded DNA molecule). Thus, these vaccines do not present infectious or oncogenic risk, as they only stimulate specific antibodies $(151,152)$. The objectives of the vaccination are (151): i) Providing prophylaxis of HPV infection by stimulating mediated humoral immunity and preventing the virus from reaching the target (keratinocytes); and ii) stimulation of cell-mediated immunity (T helper lymphocytes) as the body must destroy the abnormal keratinocytes and eliminate the lesions induced by infection.

Due to ethical reasons, the rate of cervical cancer development or the mortality rate cannot be analyzed through long-term studies; thus, the final stages of CIN investigated were CIN2 and CIN3. It is ideal to administer the vaccine prior to the commencement of sexual activities. The vaccination does not protect patients already infected with any of the strains studied (types 6,11,16, 18 and 16,18), but the tetravalent vaccine can prevent (44\%) cervical lesions in patients who have been previously infected and received only one or two of the three required doses of vaccine. The mechanisms of action of the HPV vaccines are presented in Fig. 2.

The tetravalent vaccine (Gardasil or Silgard; Merck \& Co., Whitehouse Station, NJ, USA) was approved in June 2006 for women aged between 19-26 years to prevent cervical, vulvar and vaginal cancer caused by HPV types 16 and 18, and genital lesions caused by HPV types 6, 11, 16 and 18 . The bivalent vaccine (Cervarix; GlaxoSmithKline Biologicals, Rockville, MD, USA) was approved in the USA only in October 2009, two years later than in the rest of the countries. Gardasil is a prophylactic vaccine that prevents intraepithelial cervical neoplasia, intraepithelial vulvar neoplasia and intraepithelial vaginal neoplasia, recommended to be administered prior to sexual intercourse. The double-blind clinical trial required for the approval of the vaccine was performed on 12,000 women aged between 16 and 26 years, in thirteen countries, and studies are currently being conducted to approve the vaccine for women aged between 27 and 45 years (153). An important aspect is that this vaccine is also effective for men, protecting them from pre-cancerous lesions or anal cancer caused by some HPV strains. Its use for this purpose has been permitted since October 2009 (the age category for men is 9-15 years). The vaccine dose is $0.5 \mathrm{ml}$ administered intramuscularly (never intravenously) at 2 and 4 months, respectively, from the previous dose (3 in total) and contains the following: $20 \mu \mathrm{g}$ of L1 type 6 protein, $40 \mu \mathrm{g}$ of L1 type 11 protein, $40 \mu \mathrm{g} \mathrm{L} 1$ type 16 proteins and $20 \mu \mathrm{g}$ of L1 type 18 protein. The L1 protein is in the form of virus-like particles produced on yeast cells, Saccharomyces cerevisiae strain 1895 , by recombinant DNA technology (152). The vaccine's effectiveness against HPV infection is almost $100 \%$ for strains $6,11,16$ and 18 over a period of $>4$ years. In addition, it has been shown to have an affect (38\%) on another 10 strains responsible for carcinogenesis. The reported side-effects range from swelling of the area of administration, local pain (stronger than with other vaccines), syncope, Guillain-Barre syndrome (acute demyelinating inflammatory polyneuropathy triggered by acute infectious disease) to pulmonary embolism and death 1:1,000,000, with approximately 20 cases out of total doses administered worldwide. The vaccine does not contain mercury, thiomersal (high potency toxic organomercury compound), antibiotics or viral genome traces, but contains $50 \mathrm{mcg}$ of polysorbate 80 that can cause infertility, being one of the main reasons why its use is not universally accepted. Unfortunately, as a new vaccine, long-term effects (including 
the effects on pregnancy/breastfeeding) are not yet known; however, from the current perspective, the benefits (both pathological and financial) are greater than the risks of using it (154).

Cervarix (Merck \& Co.) is a bivalent vaccine designed to prevent HPV types 18 and 16 infection (the latter is also associated with oropharyngeal cancers), clinical tests showing that it also offers some protection against strains 45 and 31 (155). The vaccine contains $20 \mu \mathrm{g}$ of L1 type 16 protein, $20 \mu \mathrm{g}$ of L1 type 18 protein, $50 \mu \mathrm{g}$ of AS043-O-desacil-4'-monophosphoryl lipid A (MPL) adjuvant which generates and maintains longer immune response to the body, absorbed on aluminum hydroxide hydrate $(0.5 \mathrm{mg}$ of aluminum). It is not recommended for patients with severe fever or immunodeficiency (these contraindications also apply to Gardasil). Compared to Gardasil, Cervarix generates twice as many anti-HPV 16 antibodies and 6-fold more anti-HPV 18 antibodies at 7 months post-dosing, but was not active on strains 6 and 11 responsible for genital warts or in the case of male patients (156). In spite of these findings and recent studies, anti-HPV vaccination remains an open subject because of multiple unclear aspects: Long-term side effects, duration of immunogenicity, effective efficacy of male patients and, last but not least, the effects on the Papanicolau test or colposcopy (the intervals between the tests could increase.

\section{Conclusions}

HPV infections are strongly implicated in the pathogenesis of different types of cancer. The screening for HPV is necessary in carcinoma therapy determination and prognosis evaluation.

\section{Competing interests}

Demetrios A. Spandidos is the Editor-in-Chief for the journal, but had no personal involvement in the reviewing process, or any influence in terms of adjudicating on the final decision, for this article.

\section{References}

1. zur Hausen H: Papillomaviruses and cancer: From basic studies to clinical application. Nat Rev Cancer 2: 342-350, 2002.

2. Ramqvist T, Grün $\mathrm{N}$ and Dalianis T: Human papillomavirus and tonsillar and base of tongue cancer. Viruses 7: 1332-1343, 2015.

3. Lacey CJ, Lowndes CM and Shah KV: Chapter 4: Burden and management of non-cancerous HPV-related conditions: HPV-6/11 disease. Vaccine 24 (Suppl 3): S3/35-41, 2006.

4. Cogliano V, Baan R, Straif K, Grosse Y, Secretan B and El Ghissassi F; WHO International Agency for Research on Cancer: Carcinogenicity of human papillomaviruses. Lancet Oncol 6: 204 2005.

5. Clifford GM, Smith JS, Plummer M, Muñoz N and Franceschi S Human papillomavirus types in invasive cervical cancer worldwide: A meta-analysis. Br J Cancer 88: 63-73, 2003.

6. Mammas IN, Sourvinos G and Spandidos DA: The paediatric story of human papillomavirus (Review). Oncol Lett 8: 502-506, 2014.

7. Mammas IN, Vageli D and Spandidos DA: Geographic variations of human papilloma virus infection and their possible impact on the effectiveness of the vaccination programme. Oncol Rep 20: 141-145, 2008.

8. Workowski KA and Bolan GA; Centers for Disease Control and Prevention: Sexually transmitted diseases treatment guidelines, 2015. MMWR Recomm Rep 64 (No. RR-3): 1-137, 2015.

9. Workowski KA and Berman S; Centers for Disease Control and Prevention (CDC): Sexually transmitted diseases treatment guidelines, 2010. MMWR Recomm Rep 59: 1-110, 2010.
10. de Villiers EM, Fauquet C, Broker TR, Bernard HU and zur Hausen H: Classification of papillomaviruses. Virology 324: 17-27, 2004.

11. Stokley S, Jeyarajah J, Yankey D, Cano M, Gee J, Roark J, Curtis RC and Markowitz L; Immunization Services Division, National Center for Immunization and Respiratory Diseases, CDC; Centers for Disease Control and Prevention (CDC): Human papillomavirus vaccination coverage among adolescents, 2007-2013, and postlicensure vaccine safety monitoring, 2006-2014-United States. MMWR Morb Mortal Wkly Rep 63: 620-624, 2014.

12. Chaturvedi AK, Engels EA, Pfeiffer RM, Hernandez BY, Xiao W, Kim E, Jiang B, Goodman MT, Sibug-Saber M, Cozen W, et al: Human papillomavirus and rising oropharyngeal cancer incidence in the United States. J Clin Oncol 29: 4294-4301, 2011.

13. Castle PE, Schiffman M, Herrero R, Hildesheim A, Rodriguez AC, Bratti MC, Sherman ME, Wacholder S, Tarone R and Burk RD: A prospective study of age trends in cervical human papillomavirus acquisition and persistence in Guanacaste, Costa Rica. J Infect Dis 191: 1808-1816, 2005

14. Sedlacek TV, Lindheim S, Eder C, Hasty L, Woodland M, Ludomirsky A and Rando RF: Mechanism for human papillomavirus transmission at birth. Am J Obstet Gynecol 161: 55-59, 1989.

15. Roman A and Fife K: Human papillomavirus DNA associated with foreskins of normal newborns. J Infect Dis 153: 855-861, 1986

16. Rintala MA, Grénman SE, Järvenkylä ME, Syrjänen KJ and Syrjänen SM: High-risk types of human papillomavirus (HPV) DNA in oral and genital mucosa of infants during their first 3 years of life: Experience from the Finnish HPV Family Study. Clin Infect Dis 41: 1728-1733, 2005.

17. Boda D, Neagu M, Constantin C, Voinescu RN, Caruntu C, Zurac S, Spandidos DA, Drakoulis N, Tsoukalas D and Tsatsakis AM: HPV strain distribution in patients with genital warts in a female population sample. Oncol Lett 12: 1779-1782, 2016.

18. Chen R, Sehr P, Waterboer T, Leivo I, Pawlita M, Vaheri A and Aaltonen LM: Presence of DNA of human papillomavirus 16 but no other types in tumor-free tonsillar tissue. J Clin Microbiol 43: 1408-1410, 2005.

19. Powell J, Strauss S, Gray J and Wojnarowska F: Genital carriage of human papilloma virus (HPV) DNA in prepubertal girls with and without vulval disease. Pediatr Dermatol 20: 191-194, 2003.

20. De Marco F: Oxidative stress and HPV carcinogenesis. Viruses 5: 708-731, 2013.

21. Căruntu C, Boda D, Musat S, Căruntu A and Mandache E: Stressinduced mast cell activation in glabrous and hairy skin. Mediators Inflamm 2014: 105950, 2014.

22. Căruntu C, Grigore C, Căruntu A, Diaconeasa A and Boda D: The role of stress in skin disease. Intern Med 8: 73-84, 2003.

23. Fang CY, Miller SM, Bovbjerg DH, Bergman C, Edelson MI, Rosenblum NG, Bove BA, Godwin AK, Campbell DE and Douglas SD: Perceived stress is associated with impaired T-cell response to HPV16 in women with cervical dysplasia. Ann Behav Med 35: 87-96, 2008.

24. Leemans CR, Braakhuis BJ and Brakenhoff RH: The molecular biology of head and neck cancer. Nat Rev Cancer 11: 9-22, 2011.

25. Gillison ML, Castellsagué X, Chaturvedi A, Goodman MT, Snijders P, Tommasino M, Arbyn M and Franceschi S: Eurogin Roadmap: Comparative epidemiology of HPV infection and associated cancers of the head and neck and cervix. Int J Cancer 134: 497-507, 2014.

26. Giuliano AR, Nyitray AG, Kreimer AR, Pierce Campbell CM, Goodman MT, Sudenga SL, Monsonego J and Franceschi S: EUROGIN 2014 roadmap: Differences in human papillomavirus infection natural history, transmission and human papillomavirus-related cancer incidence by gender and anatomic site of infection. Int J Cancer 136: 2752-2760, 2015.

27. Ang KK, Harris J, Wheeler R, Weber R, Rosenthal DI, NguyenTân PF, Westra WH, Chung CH, Jordan RC, Lu C, et al: Human papillomavirus and survival of patients with oropharyngeal cancer. N Engl J Med 363: 24-35, 2010.

28. Gillison ML, Alemany L, Snijders PJ, Chaturvedi A, Steinberg BM, Schwartz S and Castellsagué X: Human papillomavirus and diseases of the upper airway: Head and neck cancer and respiratory papillomatosis. Vaccine 30 (Suppl 5): F34-F54, 2012.

29. Doorbar J, Quint W, Banks L, Bravo IG, Stoler M, Broker TR and Stanley MA: The biology and life-cycle of human papillomaviruses. Vaccine 30 (Suppl 5): F55-F70, 2012. 
30. Sepiashvili L, Bruce JP, Huang SH, O'Sullivan B, Liu FF and Kislinger T: Novel insights into head and neck cancer using next-generation 'omic' technologies. Cancer Res 75: 480-486, 2015.

31. Psyrri A, Rampias T and Vermorken JB: The current and future impact of human papillomavirus on treatment of squamous cell carcinoma of the head and neck. Ann Oncol 25: 2101-2115, 2014.

32. Ghita MA, Caruntu C, Lixandru D, Pitea A, Batani A and Boda D: The quest for novel biomarkers in early diagnosis of diabetic neuropathy. Curr Proteomics 14: 86-99, 2017.

33. Hoadley KA, Yau C, Wolf DM, Cherniack AD, Tamborero D, Ng S, Leiserson MDM, Niu B, McLellan MD, Uzunangelov V, et al; Cancer Genome Atlas Research Network: Multiplatform analysis of 12 cancer types reveals molecular classification within and across tissues of origin. Cell 158: 929-944, 2014.

34. Termine N, Giovannelli L, Matranga D, Caleca MP, Bellavia C Perino A and Campisi G: Oral human papillomavirus infection in women with cervical HPV infection: New data from an Italian cohort and a metanalysis of the literature. Oral Oncol 47: 244-250, 2011

35. Hakenberg OW, Compérat EM, Minhas S, Necchi A, Protzel C and Watkin N; European Association of Urology: EAU guidelines on penile cancer: 2014 update. Eur Urol 67: 142-150, 2015.

36. Lupu M, Caruntu A, Caruntu C, Papagheorghe LML, Ilie MA, Voiculescu V, Boda D, Constantin C, Tanase C, Sifaki M, et al: Neuroendocrine factors: The missing link in non melanoma skin cancer (Review). Oncol Rep 38: 1327-1340, 2017.

37. Spiess PE, Dhillon J, Baumgarten AS, Johnstone PA and Giuliano AR: Pathophysiological basis of human papillomavirus in penile cancer: Key to prevention and delivery of more effective therapies. CA Cancer J Clin 66: 481-495, 2016.

38. Siegel RL, Miller KD and Jemal A: Cancer statistics, 2016. CA Cancer J Clin 66: 7-30, 2016.

39. Kayes O, Ahmed HU, Arya M and Minhas S: Molecular and genetic pathways in penile cancer. Lancet Oncol 8: 420-429, 2007.

40. Protzel C and Spiess PE: Molecular research in penile cancer-lessons learned from the past and bright horizons of the future? Int J Mol Sci 14: 19494-19505, 2013.

41. Schiller JT, Day PM and Kines RC: Current understanding of the mechanism of HPV infection. Gynecol Oncol 118 (Suppl): S12-S17, 2010

42. Steben M and Duarte-Franco E: Human papillomavirus infection: Epidemiology and pathophysiology. Gynecol Oncol 107 (Suppl 1): S2-S5, 2007.

43. Fuchs E and Nowak JA: Building epithelial tissues from skin stem cells. Cold Spring Harb Symp Quant Biol 73: 333-350, 2008.

44. Ledwaba T, Dlamini Z, Naicker S and Bhoola K: Molecular genetics of human cervical cancer: Role of papillomavirus and the apoptotic cascade. Biol Chem 385: 671-682, 2004

45. Neagu M, Căruntu C, Constantin C, Boda D, Zurac S, Spandidos DA and Tsatsakis AM: Chemically induced skin carcinogenesis: Updates in experimental models (Review). Oncol Rep 35: 2516-2528, 2016.

46. Castellsagué $X$, Bosch FX and Muñoz N: Environmental co-factors in HPV carcinogenesis. Virus Res 89: 191-199, 2002.

47. Bosch FX and Muñoz N: The viral etiology of cervical cancer Virus Res 89: 183-190, 2002

48. Satterwhite CL, Torrone E, Meites E, Dunne EF, Mahajan R, Ocfemia MC, Su J, Xu F and Weinstock H: Sexually transmitted infections among US women and men: Prevalence and incidence estimates, 2008. Sex Transm Dis 40: 187-193, 2013.

49. Nielsen A, Kjaer SK, Munk C and Iftner T: Type-specific HPV infection and multiple HPV types: Prevalence and risk factor profile in nearly 12,000 younger and older Danish women. Sex Transm Dis 35: 276-282, 2008 .

50. Skaaby S and Kofoed K: Anogenital warts in Danish men who have sex with men. Int J STD AIDS 22: 214-217, 2011

51. Owusu-Edusei K Jr, Chesson HW, Gift TL, Tao G, Mahajan R, Ocfemia MC and Kent CK: The estimated direct medical cost of selected sexually transmitted infections in the United States, 2008. Sex Transm Dis 40: 197-201, 2013.

52. World Health Organization: Implementation of the global strategy for prevention and control of sexually transmitted infections: 2006-2015. http://apps.who.int/iris/bitstream/10665/1 83117/1/9789241508841_eng.pdf. Accessed Dec 21, 2015.

53. de Sanjosé S, Diaz M, Castellsagué X, Clifford G, Bruni L, Muñoz N and Bosch FX: Worldwide prevalence and genotype distribution of cervical human papillomavirus DNA in women with normal cytology: A meta-analysis. Lancet Infect Dis 7: 453-459, 2007.
54. Newman L, Rowley J, Vander Hoorn S, Wijesooriya NS, Unemo M, Low N, Stevens G, Gottlieb S, Kiarie J and Temmerman M: Global estimates of the prevalence and incidence of four curable sexually transmitted infections in 2012 based on systematic review and global reporting. PLoS One 10: e0143304, 2015.

55. McQuillan G, Kruszon-Moran D, Markowitz LE, Unger ER, and Paulose-Ram R: Prevalence of HPV in adults aged 18-69: United States, 2011-2014. NCHS Data Brief (280): 1-8, 2017.

56. Braaten KP and Laufer MR: Human papillomavirus (HPV), HPV-related disease, and the HPV vaccine. Rev Obstet Gynecol 1 : 2-10, 2008.

57. Dunne EF and Markowitz LE: Genital human papillomavirus infection. Clin Infect Dis 43: 624-629, 2006.

58. Cai T, Wagenlehner FM, Mondaini N, D'Elia C, Meacci F, Migno S, Malossini G, Mazzoli S and Bartoletti R: Effect of human papillomavirus and Chlamydia trachomatis co-infection on sperm quality in young heterosexual men with chronic prostatitis-related symptoms. BJU Int 113: 281-287, 2014.

59. Panatto D, Amicizia D, Bianchi S, Frati ER, Zotti CM, Lai PL, Domnich A, Colzani D, Gasparini R and Tanzi E: Chlamydia trachomatis prevalence and chlamydial/HPV co-infection among HPV-unvaccinated young Italian females with normal cytology. Hum Vaccin Immunother 11: 270-276, 2015.

60. Smith JS, Muñoz N, Herrero R, Eluf-Neto J, Ngelangel C, Franceschi S, Bosch FX, Walboomers JMM and Peeling RW: Evidence for Chlamydia trachomatis as a human papillomavirus cofactor in the etiology of invasive cervical cancer in Brazil and the Philippines. J Infect Dis 185: 324-331, 2002.

61. Tarallo PA, Smolowitz J, Carriero D, Tarallo J, Siegel A, Jia H and Emond JC: Prevalence of high-risk human papilloma virus among women with hepatitis $\mathrm{C}$ virus before liver transplantation. Transpl Infect Dis 15: 400-404, 2013.

62. Smith JS, Herrero R, Bosetti C, Muñoz N, Bosch FX, Eluf-Neto J, Castellsagué X, Meijer CJ, Van den Brule AJ, Franceschi S and Ashley R; International Agency for Research on Cancer (IARC) Multicentric Cervical Cancer Study Group: Herpes simplex virus-2 as a human papillomavirus cofactor in the etiology of invasive cervical cancer. J Natl Cancer Inst 94 : 1604-1613, 2002

63. Global Burden of Disease Study 2013 Collaborators: Global, regional, and national incidence, prevalence, and years lived with disability for 301 acute and chronic diseases and injuries in 188 countries, 1990-2013: A systematic analysis for the Global Burden of Disease Study 2013. Lancet 386: 743-800, 2013.

64. Alberts CJ, Schim van der Loeff MF, Papenfuss MR, da Silva RJC, Villa LL, Lazcano-Ponce E, Nyitray AG and Giuliano AR: Association of Chlamydia trachomatis infection and herpes simplex virus type 2 serostatus with genital human papillomavirus infection in men: The HPV in men study. Sex Transm Dis 40: 508-515, 2013.

65. Mbulawa ZZ, Coetzee D, Marais DJ, Kamupira M, Zwane E, Allan B, Constant D, Moodley JR, Hoffman M and Williamson AL: Genital human papillomavirus prevalence and human papillomavirus concordance in heterosexual couples are positively associated with human immunodeficiency virus coinfection. J Infect Dis 199: 1514-1524, 2009.

66. Bruni L, Diaz M, Castellsagué X, Ferrer E, Bosch FX and de Sanjosé S: Cervical human papillomavirus prevalence in 5 continents: Meta-analysis of 1 million women with normal cytological findings. J Infect Dis 12: 1789-1799, 2010.

67. Clifford GM, Gonçalves MA and Franceschi S; HPV and HIV Study Group: Human papillomavirus types among women infected with HIV: A meta-analysis. AIDS 20: 2337-2344, 2006.

68. Koshiol J, Lindsay L, Pimenta JM, Poole C, Jenkins D and Smith JS: Persistent human papillomavirus infection and cervical neoplasia: A systematic review and meta-analysis. Am J Epidemiol 168: 123-137, 2008.

69. van Rijn VM,Mooij SH, Mollers M,Snijders PJF,Speksnijder AGCL, King AJ, de Vries HJ, van Eeden A, van der Klis FR, de Melker HE, et al: Anal, penile, and oral high-risk HPV infections and HPV seropositivity in HIV-positive and HIV-negative men who have sex with men. PLoS One 9: e92208, 2014.

70. Kjær SK, Frederiksen K, Munk C and Iftner T: Long-term absolute risk of cervical intraepithelial neoplasia grade 3 or worse following human papillomavirus infection: Role of persistence. J Natl Cancer Inst 102: 1478-1488, 2010.

71. Nielsen A, Kjaer SK, Munk C, Osler M and Iftner T: Persistence of high-risk human papillomavirus infection in a population-based cohort of Danish women. J Med Virol 82: 616-23, 2010 
72. Fukuchi E, Sawaya GF, Chirenje M, Magure T, Tuveson J, Ma Y Shiboski S, Da Costa M, Palefsky J, Moscicki AB, et al: Cervical human papillomavirus incidence and persistence in a cohort of HIV-negative women in Zimbabwe. Sex Transm Dis 36: 305-311, 2009.

73. Paaso AE, Louvanto K, Syrjänen KJ, Waterboer T, Grénman SE, Pawlita M and Syrjänen SM: Lack of type-specific concordance between human papillomavirus (HPV) serology and HPV DNA detection in the uterine cervix and oral mucosa. J Gen Virol 92: 2034-2046, 2011.

74. Syrjänen K, Shabalova I, Naud P, Kozachenko V, Derchain S, Zakharchenko S, Roteli-Martins C, Nerovjna R, Longatto-Filho A, Kljukina L, et al; New Independent States of the Former Soviet Union and the Latin American Screening Study Research Groups: Persistent high-risk human papillomavirus infections and other end-point markers of progressive cervical disease among women prospectively followed up in the New Independent States of the Former Soviet Union and the Latin American Screening study cohorts. Int J Gynecol Cancer 19: 934-942, 2009.

75. Syrjänen K, Shabalova I, Naud P, Kozachenko V, Derchain S, Zakharchenko S, Roteli-Martins C, Nerovjna R, Longatto-Filho A, Kljukina L, et al; NIS and LAMS Study Research Groups: Risk estimates for persistent high-risk human papillomavirus infections as surrogate endpoints of progressive cervical disease critically depend on reference category: Analysis of the combined prospective cohort of the New Independent States of the Former Soviet Union and Latin American Screening studies. Int J STD AIDS 22: 315-323, 2011.

76. King EM, Gilson R, Beddows S, Soldan K, Panwar K, Young C, Jit M, Edmunds WJ and Sonnenberg P: Oral human papillomavirus (HPV) infection in men who have sex with men: Prevalence and lack of anogenital concordance. Sex Transm Infect 91: 284-286, 2015.

77. Lyronis ID, Baritaki S, Bizakis I, Krambovitis E and Spandidos DA: K-ras mutation, HPV infection and smoking or alcohol abuse positively correlate with esophageal squamous carcinoma. Pathol Oncol Res 14: 267-273, 2008.

78. Zaravinos A, Bizakis J and Spandidos DA: Prevalence of human papilloma virus and human herpes virus types 1-7 in human nasal polyposis. J Med Virol 81: 1613-1619, 2009.

79. Du J, Nordfors C, Ahrlund-Richter A, Sobkowiak M, Romanitan M, Näsman A, Andersson S, Ramqvist T and Dalianis T: Prevalence of oral human papillomavirus infection among youth, Sweden. Emerg Infect Dis 18: 1468-1471, 2012.

80. Nielsen A, Kjaer SK, Munk C, Osler M and Iftner T: Persistence of high-risk human papillomavirus infection in a population-based cohort of Danish women. J Med Virol 82: 616-623, 2010.

81. Rosa MI, Fachel JM, Rosa DD, Medeiros LR, Igansi CN and Bozzetti MC: Persistence and clearance of human papillomavirus infection: A prospective cohort study. Am J Obstet Gynecol 199: 617.e1-617.e7, 2008

82. Koskimaa HM, Waterboer T, Pawlita M, Grénman S, Syrjänen K and Syrjänen S: Human papillomavirus genotypes present in the oral mucosa of newborns and their concordance with maternal cervical human papillomavirus genotypes. J Pediatr 160: 837-843, 2012.

83. Kofoed K, Sand C, Forslund O and Madsen K: Prevalence of human papillomavirus in anal and oral sites among patients with genital warts. Acta Derm Venereol 94: 207-211, 2014

84. Jang MK, Anderson DE, van Doorslaer K and McBride AA: A proteomic approach to discover and compare interacting partners of papillomavirus E2 proteins from diverse phylogenetic groups. Proteomics 15: 2038-2050, 2015.

85. Yarbro CH, Wujcik D and Gobel BH: Cancer Nursing: Principles and Practice. 7th edition. Jones \& Bartlett Learning, Burlington, MA, 2010

86. Markowitz LE, Dunne EF, Saraiya M, Chesson HW, Curtis CR, Gee J, Bocchini JA Jr and Unger ER; Centers for Disease Control and Prevention (CDC): Human papillomavirus vaccination: Recommendations of the Advisory Committee on Immunization Practices (ACIP). MMWR Recomm Rep 63: 1-30, 2014.

87. Clifford GM, Rana RK, Franceschi S, Smith JS, Gough G and Pimenta JM: Human papillomavirus genotype distribution in low-grade cervical lesions: Comparison by geographic region and with cervical cancer. Cancer Epidemiol Biomarkers Prev 14 1157-1164, 2005 .

88. Clifford GM, Smith JS, Aguado T and Franceschi S: Comparison of HPV type distribution in high-grade cervical lesions and cervical cancer: A meta-analysis. Br J Cancer 89: $101-105,2003$
89.Louvanto K, Rautava J, Willberg J, Wideman L, Syrjänen K, Grénman S and Syrjänen S: Genotype-specific incidence and clearance of human papillomavirus in oral mucosa of women: A six-year follow-up study. PLoS One 8: e53413, 2013.

90. Wu DW, Chuang CY, Lin WL, Sung WW, Cheng YW and Lee H: Paxillin promotes tumor progression and predicts survival and relapse in oral cavity squamous cell carcinoma by microRNA-218 targeting. Carcinogenesis 35: 1823-1829, 2014.

91. Martínez-Noël G, Galligan JT, Sowa ME, Arndt V, Overton TM Harper JW and Howley PM: Identification and proteomic analysis of distinct UBE3A/E6AP protein complexes. Mol Cell Biol 32: 3095-3106, 2012

92. McBride AA: The papillomavirus E2 proteins. Virology 445: 57-79, 2013.

93.Jang MK, Shen K and McBride AA: Papillomavirus genomes associate with BRD4 to replicate at fragile sites in the host genome. PLoS Pathog 10: e1004117, 2014.

94. Bersani C, Mints M, Tertipis N, Haeggblom L, Sivars L, ÄhrlundRichter A, Vlastos A, Smedberg C, Grün N, Munck-Wikland E, et al: A model using concomitant markers for predicting outcome in human papillomavirus positive oropharyngeal cancer. Oral Oncol 68: 53-59, 2017.

95. Grace $\mathrm{M}$ and Munger K: Proteomic analysis of the gamma human papillomavirus type 197 E6 and E7 associated cellular proteins. Virology 500: 71-81, 2017.

96. Serafín-Higuera I, Garibay-Cerdenares OL, Illades-Aguiar B, Flores-Alfaro E, Jiménez-López MA, Sierra-Martínez P and Alarcón-Romero LC: Differential proteins among normal cervix cells and cervical cancer cells with HPV-16 infection, through mass spectrometry-based proteomics (2D-DIGE) in women from Southern México. Proteome Sci 14: 10, 2016.

97. Koifman L, Ornellas P, Ornellas AA, Pereira DA, Zingali BR, Cavalcanti SM, Afonso LA, Sandim V and Alves G: Proteomics analysis of tissue samples from patients with squamous cell carcinoma of the penis and positive to human papillomavirus. Int Braz J Urol 41: 642-654, 2015.

98. Tanase CP, Albulescu R and Neagu M: Application of 3D hydrogel microarrays in molecular diagnostics: Advantages and limitations. Expert Rev Mol Diagn 11: 461-464, 2011

99. Ewaisha R, Meshay I, Resnik J, Katchman BA and Anderson KS Programmable protein arrays for immunoprofiling HPV-associated cancers. Proteomics 16: 1215-1224, 2016.

100. Arroyo Mühr LS, Hultin E, Bzhalava D, Eklund C, Lagheden C, Ekström J, Johansson H, Forslund O and Dillner J: Human papillomavirus type 197 is commonly present in skin tumors. Int J Cancer 136: 2546-2555, 2015.

101. Dahlgren L, Mellin H, Wangsa D, Heselmeyer-Haddad K, Björnestål L, Lindholm J, Munck-Wikland E, Auer G, Ried T and Dalianis T: Comparative genomic hybridization analysis of tonsillar cancer reveals a different pattern of genomic imbalances in human papillomavirus-positive and -negative tumors. Int J Cancer 107: 244-249, 2003

102. Mountzios G, Rampias T and Psyrri A: The mutational spectrum of squamous-cell carcinoma of the head and neck: Targetable genetic events and clinical impact. Ann Oncol 25: 1889-1900, 2014.

103. Smeets SJ, Braakhuis BJ, Abbas S, Snijders PJ, Ylstra B, van de Wiel MA, Meijer GA, Leemans CR and Brakenhoff RH: Genome-wide DNA copy number alterations in head and neck squamous cell carcinomas with or without oncogene-expressing human papillomavirus. Oncogene 25: 2558-2564, 2006.

104. Hajek M, Sewell A, Kaech S, Burtness B, Yarbrough WG and Issaeva N: TRAF3/CYLD mutations identify a distinct subset of human papillomavirus-associated head and neck squamous cell carcinoma. Cancer 123: 1778-1790, 2017.

105. Henderson S, Chakravarthy A, Su X, Boshoff C and Fenton TR APOBEC-mediated cytosine deamination links PIK3CA helical domain mutations to human papillomavirus-driven tumor development. Cell Reports 7: 1833-1841, 2014.

106. Lui VW, Hedberg ML, Li H, Vangara BS, Pendleton K, Zeng Y, Lu Y, Zhang Q, Du Y, Gilbert BR, et al: Frequent mutation of the PI3K pathway in head and neck cancer defines predictive biomarkers. Cancer Discov 3: 761-769, 2013.

107. KostareliE,HolzingerD, Bogatyrova O, HielscherT,Wichmann G, Keck M, Lahrmann B, Grabe N, Flechtenmacher C, Schmidt CR, et al: HPV-related methylation signature predicts survival in oropharyngeal squamous cell carcinomas. J Clin Invest 123 : 2488-2501, 2013

108. Lechner M, Fenton T, West J, Wilson G, Feber A, Henderson S, Thirlwell C, Dibra HK, Jay A, Butcher L, et al: Identification and functional validation of HPV-mediated hypermethylation in head and neck squamous cell carcinoma. Genome Med 5: 15, 2013. 
109. de LenaPG,Paz-Gallardo A,Paramio JMand García-Escudero R Clusterization in head and neck squamous carcinomas based on lncRNA expression: Molecular and clinical correlates. Clin Epigenetics 9: 36, 2017.

110. Jung AC, Briolat J, Millon R, de Reyniès A, Rickman D, Thomas E, Abecassis J, Clavel C and Wasylyk B: Biological and clinical relevance of transcriptionally active human papillomavirus (HPV) infection in oropharynx squamous cell carcinoma. Int J Cancer 126: 1882-1894, 2010.

111. Kimple RJ, Smith MA, Blitzer GC, Torres AD, Martin JA, Yang RZ, Peet CR, Lorenz LD, Nickel KP, Klingelhutz AJ, et al: Enhanced radiation sensitivity in HPV-positive head and neck cancer. Cancer Res 73: 4791-4800, 2013.

112. Seiwert TY,Zuo Z, Keck MK, Khattri A, Pedamallu CS, Stricker T, Brown C, Pugh TJ, Stojanov P, Cho J, et al: Integrative and comparative genomic analysis of HPV-positive and HPV-negative head and neck squamous cell carcinomas. Clin Cancer Res 21: 632-641, 2015.

113. Gubanova E, Brown B, Ivanov SV, Helleday T, Mills GB, Yarbrough WG and Issaeva N: Downregulation of SMG-1 in HPV-positive head and neck squamous cell carcinoma due to promoter hypermethylation correlates with improved survival. Clin Cancer Res 18: 1257-1267, 2012.

114. Lawrence MS, Sougnez C, Lichtenstein L, Cibulskis K, Lander E, Gabriel SB, Getz G, Ally A, Balasundaram M, Birol I, et al; Cancer Genome Atlas Network: Comprehensive genomic characterization of head and neck squamous cell carcinomas. Nature 517: 576-582, 2015.

115. Pyeon D, Newton MA, Lambert PF, den Boon JA, Sengupta S, Marsit CJ, Woodworth CD, Connor JP, Haugen TH, Smith EM, et al: Fundamental differences in cell cycle deregulation in human papillomavirus-positive and human papillomavirus-negative head/neck and cervical cancers. Cancer Res 67: 4605-4619, 2007.

116. Lajer CB, Garnæs E, Friis-Hansen L, Norrild B, Therkildsen MH, Glud M, Rossing M, Lajer H, Svane D, Skotte L, et al: The role of miRNAs in human papilloma virus (HPV)-associated cancers: Bridging between HPV-related head and neck cancer and cervical cancer. Br J Cancer 106: 1526-1534, 2012.

117. Slebos RJC, Jehmlich N, Brown B, Yin Z, Chung $\mathrm{CH}$ Yarbrough WG and Liebler DC: Proteomic analysis of oropharyngeal carcinomas reveals novel HPV-associated biological pathways. Int J Cancer 132: 568-579, 2013.

118. Colacino JA, Dolinoy DC, Duffy SA, Sartor MA, Chepeha DB, Bradford CR, McHugh JB, Patel DA, Virani S, Walline HM, et al: Comprehensive analysis of DNA methylation in head and neck squamous cell carcinoma indicates differences by survival and clinicopathologic characteristics. PLoS One 8: e54742, 2013

119. Klussmann JP, Mooren JJ, Lehnen M, Claessen SM, Stenner M, Huebbers CU, Weissenborn SJ, Wedemeyer I, Preuss SF, Straetmans JM, et al: Genetic signatures of HPV-related and unrelated oropharyngeal carcinoma and their prognostic implications. Clin Cancer Res 15: 1779-1786, 2009.

120. Wilting SM, Smeets SJ, Snijders PJF, van Wieringen WN, van de Wiel MA, Meijer GA, Ylstra B, Leemans CR, Meijer CJLM, Brakenhoff RH, et al: Genomic profiling identifies common HPV-associated chromosomal alterations in squamous cell carcinomas of cervix and head and neck. BMC Med Genomics 2: 32, 2009.

121. Canham M, Charsou C, Stewart J, Moncur S, Hoodless L, Bhatia R, Cong D, Cubie H, Busby-Earle C, Williams A, et al: Increased cycling cell numbers and stem cell associated proteins as potential biomarkers for high grade human papillomavirus+ve pre-neoplastic cervical disease. PLoS One 9: el15379, 2014.

122. Van Raemdonck GAA, Tjalma WAA, Coen EP, Depuydt CE and Van Ostade XWM: Identification of protein biomarkers for cervical cancer using human cervicovaginal fluid. PLoS One 9: e106488, 2014.

123. Descamps G, Wattiez R and Saussez S: Proteomic study of HPV-positive head and neck cancers: Preliminary results. BioMed Res Int 2014: 430906, 2014.

124. Bonner JA, Harari PM, Giralt J, Azarnia N, Shin DM, Cohen RB, Jones CU, Sur R, Raben D, Jassem J, et al: Radiotherapy plus cetuximab for squamous-cell carcinoma of the head and neck. N Engl J Med 354: 567-578, 2006.

125.Leung DT, Lim PL, Cheung TH, Wong RR, Yim SF, Ng MH, Tam FC, Chung TK and Wong YF: Osteopontin fragments with intact thrombin-sensitive site circulate in cervical cancer patients. PLoS One 11: e0160412, 2016.
126. De Marco F, Bucaj E, Foppoli C, Fiorini A, Blarzino C, Filipi K, Giorgi $\mathrm{A}$, Schininà ME, Di Domenico $\mathrm{F}$, Coccia R, et al: Oxidative stress in HPV-driven viral carcinogenesis: Redox proteomics analysis of HPV-16 dysplastic and neoplastic tissues. PLoS One 7: e34366, 2012.

127. Perluigi M, Giorgi A, Blarzino C, De Marco F, Foppoli C, Di Domenico F, Butterfield DA, Schininà ME, Cini C and Coccia R: Proteomics analysis of protein expression and specific protein oxidation in human papillomavirus transformed keratinocytes upon UVB irradiation. J Cell Mol Med 13 (8B): 1809-1822, 2009.

128. Overgaard J, Eriksen JG, Nordsmark M, Alsner J and Horsman MR; Danish Head and Neck Cancer Study Group: Plasma osteopontin, hypoxia, and response to the hypoxia sensitiser nimorazole in radiotherapy of head and neck cancer: Results from the DAHANCA 5 randomised double-blind placebo-controlled trial. Lancet Oncol 6: 757-764, 2005.

129. Hassan Metwally MA, Jansen JA and Overgaard J: Study of the population pharmacokinetic characteristics of nimorazole in head and neck cancer patients treated in the DAHANCA- 5 trial. Clin Oncol (R Coll Radiol) 27: 168-175, 2015.

130.Lee KA, Kang JW, Shim JH, Kho CW, Park SG, Lee HG, Paik SG, Lim JS and Yoon DY: Protein profiling and identification of modulators regulated by human papillomavirus 16 $\mathrm{E} 7$ oncogene in $\mathrm{HaCaT}$ keratinocytes by proteomics. Gynecol Oncol 99: 142-152, 2005.

131. Thomas M, Tomaić V, Pim D, Myers MP, Tommasino M and Banks L: Interactions between E6AP and E6 proteins from alpha and beta HPV types. Virology 435: 357-362, 2013.

132. Sandberg A, Lindell G, Källström BN, Branca RM, Danielsson KG, Dahlberg M, Larson B, Forshed J and Lehtiö J: Tumor proteomics by multivariate analysis on individual pathway data for characterization of vulvar cancer phenotypes. Mol Cell Proteomics 11: M112.016998, 2012.

133. Jamison JH, Kaplan DW, Hamman R, Eagar R, Beach R and Douglas JM Jr: Spectrum of genital human papillomavirus infection in a female adolescent population. Sex Transm Dis 22: 236-243, 1995.

134. Blas MM, Brown B, Menacho L, Alva IE, Silva-Santisteban A and Carcamo C: HPV Prevalence in multiple anatomical sites among men who have sex with men in Peru. PLoS One 10: e0139524, 2015.

135.Uzawa K, Baba T, Uchida F, Yamatoji M, Kasamatsu A, Sakamoto Y, Ogawara K, Shiiba M, Bukawa H and Tanzawa H: Circulating tumor-derived mutant mitochondrial DNA: A predictive biomarker of clinical prognosis in human squamous cell carcinoma. Oncotarget 3: 670-677, 2012.

136. No. 90-IARC Working Group on the evaluation of carcinogenic risk to humans: IARC Monographs on the evaluation of carcinogenic risks to humans. IARC, Lyon, 2007.

137. Elrefaey S, Massaro MA, Chiocca S, Chiesa F and Ansarin M: HPV in oropharyngeal cancer: The basics to know in clinical practice. Acta Otorhinolaryngol Ital 34: 299-309, 2014.

138. Faridi R, Zahra A, Khan K and Idrees M: Oncogenic potential of human papillomavirus (HPV) and its relation with cervical cancer. Virol J 8: 269, 2011.

139. Hamana K, Uzawa K, Ogawara K, Shiiba M, Bukawa H, Yokoe H and Tanzawa $\mathrm{H}$ : Monitoring of circulating tumour-associated DNA as a prognostic tool for oral squamous cell carcinoma. $\mathrm{Br}$ J Cancer 92: 2181-2184, 2005.

140. Voiculescu V, Calenic B, Ghita M, Lupu M, Caruntu A, Moraru L, Voiculescu S, Ion A, Greabu M, Ishkitiev N and Caruntu C: From normal skin to squamous cell carcinoma: A quest for novel biomarkers. Dis Markers 2016: 4517492, 2016.

141.Ang KK, Harris J, Wheeler R, Weber R, Rosenthal DI, Nguyen-Tân PF, Westra WH, Chung CH, Jordan RC, Lu C, et al: Human papillomavirus and survival of patients with oropharyngeal cancer. N Engl J Med 363: 24-35, 2010.

142. Stanescu B, Miron R and Badiu C: Anaplastic carcinoma of the thyroid mimicking acute thyroiditis. Acta Endocrinol (Bucur) 3: 493-502, 2007.

143. Forastiere AA, Goepfert H, Maor M, Pajak TF, Weber R, Morrison W, Glisson B, Trotti A, Ridge JA, Chao C, et al: Concurrent chemotherapy and radiotherapy for organ preservation in advanced laryngeal cancer. N Engl J Med 349: 2091-2098, 2003.

144.Pignon JP, le Maître A, Maillard E and Bourhis J; MACH-NC Collaborative Group: Meta-analysis of chemotherapy in head and neck cancer (MACH-NC): An update on 93 randomised trials and 17,346 patients. Radiother Oncol 92: 4-14, 2009. 
145. Călina D, Docea AO, Rosu L, Zlatian O, Rosu AF, Anghelina F, Rogoveanu O, Arsene AL, Nicolae AC, Drăgoi CM, et al: Antimicrobial resistance development following surgical site infections. Mol Med Rep 15: 681-688, 2017.

146. Tănase A, Coliță A, Ianoşi G, Neagoe D, Brănişteanu DE, Călina D, Docea AO, Tsatsakis A and Ianosi SL: Rare case of disseminated fusariosis in a young patient with graft vs. host disease following an allogeneic transplant. Exp Ther Med 12: 2078-2082, 2016.

147. Mioc M, Soica C, Bercean V, Avram S, Balan-Porcarasu M, Coricovac D, Ghiulai R, Muntean D, Andrica F, Dehelean C, et al: Design, synthesis and pharmaco-toxicological assessment of 5-mercapto-1,2,4-triazole derivatives with antibacterial and antiproliferative activity. Int J Oncol 50: 1175-1183, 2017.

148. Oprean C, Borcan F, Pavel I, Dema A, Danciu C, Soica C, Dehelean C, Nicu A, Ardelean A, Cristea M, et al: In vivo biological evaluation of polyurethane nanostructures with ursolic and oleanolic acids on chemically-induced skin carcinogenesis. In Vivo 30: 633-638, 2016.

149. Sani TA, Mohammadpour E, Mohammadi A, Memariani T, Yazdi MV, Rezaee R, Calina D, Docea AO, Goumenou M, Etemad L and Shahsavand S: Cytotoxic and apoptogenic properties of Dracocephalum kotschyi aerial part different fractions on calu-6 and mehr-80 lung cancer cell lines. Farmacia 65: 189-199, 2017

150. Suzich JA, Ghim SJ, Palmer-Hill FJ, White WI, Tamura JK, Bell JA, Newsome JA, Jenson AB and Schlegel R: Systemic immunization with papillomavirus L1 protein completely prevents the development of viral mucosal papillomas. Proc Natl Acad Sci USA 92: 11553-11557, 1995.

151. Roden RB, Monie A and Wu TC: Opportunities to improve the prevention and treatment of cervical cancer. Curr Mol Med 7: 490-503, 2007.
152. Joura EA,Leodolter S,Hernandez-Avila M, Wheeler CM,Perez G, Koutsky LA, Garland SM, Harper DM, Tang GW, Ferris DG, et al: Efficacy of a quadrivalent prophylactic human papillomavirus (types 6, 11, 16, and 18) L1 virus-like-particle vaccine against high-grade vulval and vaginal lesions: A combined analysis of three randomised clinical trials. Lancet 369: 1693-1702, 2007.

153. Varsani A, Williamson AL, de Villiers D, Becker I, Christensen ND and Rybicki EP: Chimeric human papillomavirus type 16(HPV-16) L1 particles presenting the common neutralizing epitope for the L2 minor capsid protein of HPV-6 and HPV-16. J Virol 77: 8386-8393, 2003.

154. Paavonen J, Jenkins D, Bosch FX, Naud P, Salmerón J, Wheeler CM, Chow SN, Apter DL, Kitchener HC, Castellsague X, et al; HPV PATRICIA study group: Efficacy of a prophylactic adjuvanted bivalent $\mathrm{L} 1$ virus-like-particle vaccine against infection with human papillomavirus types 16 and 18 in young women: An interim analysis of a phase III double-blind, randomised controlled trial. Lancet 369: 2161-2170, 2007.

155.Panatto D, Amicizia D, Bragazzi NL, Rizzitelli E, Tramalloni D, Valle I and Gasparini R: Human papillomavirus vaccine: State of the art and future perspectives. Adv Protein Chem Struct Biol 101: 231-322, 2015.

156. Toft L, Storgaard M, Müller M, Sehr P, Bonde J, Tolstrup M, Østergaard L and Søgaard OS: Comparison of the immunogenicity and reactogenicity of Cervarix and Gardasil human papillomavirus vaccines in HIV-infected adults: A randomized, double-blind clinical trial. J Infect Dis 209: 1165-1173, 2014.

This work is licensed under a Creative Commons Attribution-NonCommercial-NoDerivatives 4.0 International (CC BY-NC-ND 4.0) License. 